\title{
Vestir la librea de Cristo. Huellas de espiritualidad martirial en San Juan de Ávila
}

\author{
María Jesús Fernández Cordero*
}

Fecha de recepción: agosto 2021

Fecha de aceptación: noviembre 2021

\section{Sumario:}

En los Procesos informativos para la beatificación de San Juan de Ávila se preguntó por su deseo de ser mártir. Tras explorar las respuestas que dieron los testigos, este artículo trata de aclarar la existencia de una espiritualidad martirial en el Maestro, en un tiempo en que se están formando las llamadas "fronteras martiriales". Estudiamos desde esta clave la experiencia en que se pudo originar -la estancia en la cárcel de Sevilla-, analizando los textos más personales en este sentido; nos acercamos a su predicación sobre el martirio y, finalmente, a su epistolario, para descubrir en sus palabras de acompañamiento espiritual lo que revelan de la existencia de esta dimensión.

\section{Palabras clave:}

Martirio; Fronteras martiriales; Persecución; Librea de Cristo; Pasión de Cristo; Imitatio Christi; Acompañamiento espiritual.

\section{Wearing de livery of Christ. Traces of mar- tyrial spirituality in San Juan de Ávila}

\begin{abstract}
:
In the informative processes for the beatification of San Juan de Ávila, it was asked about his desire to be a martyr. After exploring the answers given by the witnesses, this article tries to clarify the existence of a martyrial spirituality in the Master, at a time when the so-called "martyrdom borders" are being formed. We study from this key the experience in which could originate, the stay in the Seville prison, analysing the most personal texts in this sense; we approach his preaching on martyrdom and, finally, his epistolary, to discover in his words of spiritual accompaniment what they reveal about the existence of this dimension
\end{abstract}

\section{Keywords:}

Martyrdom; Martyrdom borders; Persecution; Livery of Christ; Passion of Christ; Imitatio Christi; Spiritual accompaniment

\footnotetext{
* Profesora del Departamento de Sagrada Escritura e Historia de la Iglesia de la Universidad Pontificia Comillas, http://orcid.org/0000-0002-3375-3231, mjfcordero@comillas.edu.
} 


\section{María Jesús Fernández Cordero}

\section{Introducción: Sobre el deseo de ser mártir en Juan de Ávila}

En los años finales del siglo XVI se inició, como consecuencia del enfrentamiento entre católicos y protestantes, el auge de una cultura martirial en Europa, de la que participó también la sociedad hispana. A partir de 1580 se difundió una abundante literatura de este tipo, cuyo discurso no fue ajeno al contexto imperial y colonial. Un reciente estudio sobre este fenómeno ha identificado, para el caso de la Monarquía Hispánica, cuatro grandes fronteras martiriales $^{1}$ : 1) la frontera de la herejía, representada por la persecución de los católicos en la Inglaterra de Isabel I; 2) la frontera de la infidelidad, definida por el enfrentamiento con los musulmanes en el Mediterráneo, que dio lugar a la literatura sobre el cautiverio de los cristianos en tierras de Argel y Túnez; 3) la frontera del paganismo civilizado, con la violenta persecución del cristianismo en el Japón de la primera mitad del siglo XVII; y 4) la frontera del paganismo salvaje, con las crónicas martiriales de los jesuitas en las misiones americanas, también del siglo XVII.

Evidentemente, Juan de Ávila († 1569) no llegó a contemplar este proceso, aunque es posible establecer nexos con las fronteras que ya en su tiempo se iban erigiendo como lugares de confrontación. De la primera de ellas, debió tener noticias por su relación con don Gómez Suárez de Figueroa, hijo de doña Catalina Fernández de Córdoba, marquesa de Priego; don Gómez acompañó al príncipe Felipe a Inglaterra en 1554, en 1556 entró en el Consejo de Estado y se casó en 1558 con Jane Dormer, dama de la reina María Tudor; fue embajador ordinario en la Inglaterra de Isabel I hasta mayo de 1559, pero tuvo que abandonar el país al ser considerado enemigo y, junto con su esposa, favoreció la protección de los exiliados ingleses en la corte hispana; en 1567 obtuvo el rango ducal para la casa de Feria. Sabemos que Ávila medió en el conflicto que se produjo entre don Gómez y su madre a causa de su matrimonio, que afectó a la política de linaje trazada por la marquesa ${ }^{2}$. Y resulta interesante constatar que, entre los libros de su biblioteca, figura la primera edición (Co-

\footnotetext{
${ }^{1}$ Alejandro Cañeque, Un imperio de mártires. Religión y poder en las fronteras de la Monarquía Hispánica (Madrid: Marcial Pons, 2020), 19-23. Véase también José Luis Beltrán, "«Aun a costa de la propia vida». Martirio y misión en el mundo ibérico de la Edad Moderna", en Identidades y fronteras culturales en el mundo ibérico en la Edad Moderna, eds. José Luis Bertrán, Bernat Hernández y Doris Moreno (Barcelona: Universitat Autònoma de Barcelona, 2016), 283-295.

${ }^{2}$ María Jesús Fernández Cordero, Juan de Ávila (1499?-1569). Tiempo, vida y espiritualidad (Madrid: BAC, 2017), 256-260. Santiago Fernández Conti, "Suárez de Figueroa, Gómez (I duque de Feria)", en Felipe II (1527-1598). La Configuración de la Monarquía Hispánica, dirs. José Martínez Millán y Carlos J. de Carlos Morales (Salamanca: Junta de Castilla y León, 1998), 484-485. Manuel Fernández Álvarez, Tres embajadores de Felipe II en Inglaterra (Madrid: CSIC, 1951), 19-54.
} 
lonia 1527) de un tratadito de John Fisher (obispo de Rochester, decapitado en 1535) sobre la eucaristía contra la doctrina de Ecolampadio, entre otras obras de controversia ${ }^{3}$.

Mucho más temprana y cercana debió ser para Ávila la frontera de la infidelidad, pues en Sevilla su actividad pastoral se entrelazó con la de Fernando de Contreras, a quien quizás ya había conocido en Alcalá; a partir de 1532, Contreras se dedicó con gran empeño a la redención de cautivos, pasando unas diez veces al norte de África ${ }^{4}$. Parece que el Maestro recomendó este tipo de acciones redentoras hasta el final de su vida, como hizo con la beata de Granada llamada Constanza de Ávila 5 . Pero, sobre todo, él mismo desarrolló su pastoral en lo que la historiografía actual llama "nueva frontera", o "frontera interior", definida por la importancia de la población morisca ${ }^{6}$. Es muy reveladora la dedicación de algunos de sus discípulos a estas comunidades ${ }^{7}$, destacando en ello Hernán Núñez, que predicó en las Alpujarras, Hernando de Vargas, que fue cura en Berja, o los jesuitas que trabajaron en el Albaicín de Granada; seguramente avilista fue también el sacerdote Juan Fernández, oriundo como él de Almodóvar del Campo, del que se dice que "murió mártir" cuando enseñaba la doctrina en el reino de Granada ${ }^{8}$. Podemos suponer que, meses antes de morir, Ávila tendría noticia del inicio de la guerra de las Alpujarras en la navidad de 1568 y de los acontecimientos que, interpretados como hechos martiriales, se integrarían después en una tradición sostenida por

\footnotetext{
${ }^{3}$ Miguel Ángel Sánchez Herrador y Raúl Manchón Gómez, "La biblioteca de Juan de Ávila del colegio jesuítico de Montilla", en El Maestro Juan de Ávila (1500?-1569). Un exponente del humanismo reformista, eds. Ma Dolores Rincón González y Raúl Manchón Gómez (Madrid: FUE, 2014), 450.

${ }^{4}$ Gabriel Aranda, Vida del siervo de Dios exemplar de sacerdotes el Venerable Padre Fernando de Contreras, natural de esa ciudad de Sevilla, del hábito clerical de N. P. S. Pedro (Sevilla: Tomás López de Haro, 1692). Fernández Cordero, Juan de Ávila, 104-105.

${ }^{5}$ Proceso de beatificación del Maestro Juan de Ávila, ed. José Luis Martínez Gil (Madrid: BAC, 2004) 47. Es la declaración del jesuita Pedro de Vargas en el Proceso en Madrid. En adelante indicaremos los lugares del Proceso siempre por esta edición. De esta mujer se dice que era discípula de Ávila "desde mui moza" (ib., 46) y que estando él "ya mui malo de la enfermedad de que murió", le encargó "sacase cinco niñas de cautiverio", cosa que ella hizo a través de los mercedarios de Granada, pagando el rescate; repitió este acto para otras cinco.

${ }^{6}$ Manuel Barrios Aguilera, "La nueva frontera. El reino de Granada ante el mundo islámico en el siglo XVI", en Actas del Congreso la Frontera Oriental Nazarí como sujeto histórico (s. XIII-XVI): Lorca-Vera, 22 a 24 de noviembre de 1994, coord. Pedro Segura Artero (Almería: Instituto de Estudios Almerienses, 1994), 583-610.

7 Juan Ignacio Pulido Serrano, "Juan de Ávila y el problema morisco", en Juan de Ávila, unicus et multiplex. Una visión multidisciplinar, ed. $\mathrm{M}^{\mathrm{a}}$ Dolores Rincón González, Ignacio Pulido Serrano y Natalia Soria Ruiz (Madrid: Fundación Universitaria Española - Universidad Pontificia de Salamanca, 2021), 707-731; Mohamed Saadan, "La minoría morisca en la percepción y legado escrito de Juan de Ávila”, en Juan de Ávila, unicus..., 733-749.

${ }^{8}$ Proceso en Almodóvar del Campo, 69, 73, 78 y 99.
} 


\section{María Jesús Fernández Cordero}

los descendientes de los "mártires" y elaborada en las crónicas de la época y la política eclesiástica9.

En tiempos de Ávila se estaba abriendo la frontera del paganismo civilizado. Hasta 1597 no llegarían los primeros mártires, con la ejecución -crucificados y atravesados por lanzadas- de veintiséis cristianos en Nagasaki ${ }^{10}$. Pero, por su relación con los jesuitas, Ávila tenía noticias de las misiones en Japón: en la misma carta al arzobispo Pedro Guerrero (de 22 de diciembre de 1564) en que le recomienda enviar predicadores y confesores "por los lugares donde moran cristianos nuevos y de los moriscos" y le propone para ello a Hernán Núñez, al hablar del valor del ejemplo de vida, escribe: "Dícenme que en lo que en la tierra del Japón más mueve a los gentiles a convertirse por los de la Compañía es ver que han ido tantas leguas de tierra y mar a buscar la salvación de ellos, sin propio interés y con grandes trabajos y peligros de muerte" ${ }^{11}$.

De los comienzos de su ministerio data la referencia, más personal, a la frontera americana, a causa de su intención de viajar a Nueva España con el dominico Fr. Julián Garcés ${ }^{12}$.

Fue este frustrado proyecto de pasar a Indias el que proporcionó a la hagiografía avilista del siglo XVII la oportunidad de atribuirle una vocación martirial. Ello pudo estar influido por el avance de esta cultura a que nos hemos referido, pero también por la progresiva exigencia de verificación de la heroicidad de las virtudes para los procesos de canonización, que se fue imponiendo después de Trento ${ }^{13}$. El lenguaje del interrogatorio de los procesos informativos para la beatificación de Âvila, elaborado en 1623, refleja algo de

\footnotetext{
${ }^{9}$ Manuel Barrios Aguilera y Valeriano Sánchez Ramos, Martirios y mentalidad martirial en las Alpujarras (De la rebelión morisca a las Actas de Ugíjar) (Granada: Universidad de Granada, 2001).

${ }^{10}$ Alejandro Cañeque, Un imperio de mártires..., 201ss. Esther Jiménez Pablo, "El martirio en las misiones durante el siglo XVII: devoción y propaganda política", Chronica nova 43 (2017): 139-165. Los mártires de Nagasaki fueron 6 franciscanos, 3 jesuitas japoneses y 17 japoneses laicos.

${ }^{11}$ San Juan de Ávila, Carta 178, en Obras completas IV (Madrid: BAC, 2003), 592. Por esta edición (Madrid: BAC, 2000-2003, 4 vols.) citaremos los escritos de Ávila; en adelante OC seguido del número del volumen.

${ }^{12}$ La diócesis de Tlaxcala, de la que se haría cargo Garcés, estaba aún siendo definida en sus límites geográficos en 1526; el viaje lo pudo realizar en 1527, sin que Ávila se incorporara a él. Juan Pablo Salazar Andreu, "Fray Julián Garcés. El Defensor de los Indios (1527-1542)", Hipogrifo 4/2 (2016): 327-337.

${ }^{13}$ Alberto Royo Mejía, "Evolución histórica de la prueba de la heroicidad de las virtudes en las causas de los Santos en los siglos anteriores a Benedicto XIV", Archivo Teológico Granadino 56 (1993): 25-61. Giulio Sodano, "El nuevo proceso de canonización de la edad moderna", Anuario de Historia de la Iglesia 29 (2020): 53-72. Id., "Il nuovo modello di santità nell'epoca post-tridentina", en I tempi del Concilio. Religione, cultura e società nell'Europa tridentina, a cura di Cesare Mozzarelli e Danilo Zardin (Roma: Bulzoni Editore, 1997) 189-205. En esta primera mitad del s. XVII comenzó a difundirse la expresión "virtud heroica"; el primer decreto pontificio que la utilizó fue el de la beatificación de Cayetano de Thiene en 1629 (ib. 193).
} 
Vestir la librea de CRISto. Huellas de espiritualidad martirial en San Juan...

esto $^{14}$ : la pregunta 6 , sobre "la virtud de la fortaleza y perseverancia en la fe" insistía en que no solo "conservó fielmente la sana y verdadera doctrina sino que también constantemente la defendió" y "en sus sermones trabajó mucho por defender y predicar la fe católica"15; más adelante leemos:

Pregunta 10, del deseo de ser mártir: Si saben el deseo grande que el dicho Padre Maestro Ávila tuvo de morir mártir por amor de Dios y queriendo pasar con el obispo de Irescala a las Indias, con este deseo fue impedido por la buena memoria de don Alonso Manrique, Arzobispo de Sevilla, Inquisidor Mayor de estos Reinos, mandándole como su Prelado en virtud de santa obediencia que no pasase y preguntándole la causa dijo que por no privar a las ovejas de su arzobispado de la doctrina, santidad y ejemplo de un tan insigne varón le detenía, y esto a los primeros años de su Predicación ${ }^{16}$.

Esta pregunta suele pasar desapercibida, pues muchos testigos no la contestan o no saben, o se deslizan hacia la causa que impidió el viaje. Entre los que dan respuesta afirmativa sobre su deseo de ser mártir encontramos, en Almodóvar del Campo, al ermitaño Antonio Jiménez del Arcediano, que dice haberlo oído de "muchas personas devotas, religiosas de Congregaciones santas y religiosas de mugeres y hombres que fueron discípulos del dicho Venerable Padre"17. En Montilla testificó Pedro García de Molina el viejo, quien, con sus 85 años, declaró haber conocido a Ávila, aunque solo confirmó el contenido de la pregunta "por haverlo oído decir en esta Villa, viviendo en ella el dicho Maestro Ábila, a muchas personas grabes, y de crédito, y en otras partes, después de ser muerto, sin que en tiempo alguno aya oído lo contrario"18; en esta localidad, el deseo que tuvo de morir mártir se dice motivado por el amor de Dios, tal y como aparece en el enunciado de la pregunta; es calificado de "eficazíssimo" e "inttenso"19, y la testificación se apoya con frecuencia en ser algo público y notorio ${ }^{20}$. Pero también a veces se invoca la autoridad de los discípulos para sustentar el testimonio: en Montilla, la de Juan de Villarás ${ }^{21}$; en Jaén, la de Alonso

\footnotetext{
${ }^{14}$ Proceso en Madrid, 8-16. No aparece la heroicidad de las virtudes, aunque en la amplia redacción de la Pregunta 13 sobre la fe, esperanza y caridad, se averigua si "tuvo con eminencia las demás virtudes" (p. 11). Sí encontramos la expresión en el primer testigo, el licenciado Juan de Vargas, que señala "como virtud heroica en él" la honestidad (p. 27).

${ }^{15}$ Ibid., 9-10.

${ }^{16}$ Ibid., 10-11. La grafía del obispado de Garcés cambia con frecuencia en la transcripción de los procesos informativos.

${ }^{17}$ Proceso en Almodóvar del Campo, 135.

${ }^{18}$ Proceso en Montilla, 472.

${ }^{19}$ Ibid., 303 y 346.

${ }^{20}$ Ibid., 303: "sabe estte testigo por la grande publicidad y notoriedad que de ello hubo en esta Villa...".

${ }^{21}$ Ibid., 593.
} 


\section{María Jesús Fernández Cordero}

de Molina ${ }^{22}$; en Baeza, la del doctor Bernardino de Carleval $^{23} \mathrm{o}$, de modo más general, la de "los Doctores y Maestros de esta Universidad, como fue el Doctor Diego Pérez y Doctor Carleval"24. En Andújar, el P. Andrés de Cazorla, rector del colegio de la Compañía, apoya sus testimonios en Juan de Villarás y en otros discípulos, algunos de ellos jesuitas, como el P. Diego de Guzmán, pero en esta pregunta "se remite a lo que el Padre Maestro Fray Luis de Granada tiene escripto e impreso" 25 , sin mencionar para nada el deseo de martirio.

Podemos constatar que este punto del interrogatorio modificó la interpretación del hecho del frustrado viaje. En efecto, Fr. Luis de Granada, el primero en redactar una Vida de Juan de Ávila (1588), se refiere a su proyecto de pasar a Indias como una elección para servir al Señor en el lugar "donde hubiese más trabajo y más necesidad, y menos honra y aplauso del mundo"26. Su segundo biógrafo, el licenciado Luis Muñoz, que tuvo acceso a los papeles de los procesos informativos y publicó su Vida en 1635, amplificó el pasaje sobre el lugar donde Ávila deliberaba desempeñar su ministerio:

Ofreciósele las Indias, mies copiosa, por parte donde había más trabajo, más necesidad, menos honra y aplauso del mundo, y allí emplearse todo en la conversión de la gentilidad con denuedo de entrar por la tierra tan adentro que, en pago de sus servicios, pudiese esperar un glorioso martirio: que el ardor grande de amor que abrasaba ya su corazón, no se contentaba con mayor correspondencia ${ }^{27}$.

Sin embargo, el carácter hagiográfico de estas palabras y su sustentación en unos testimonios demasiado indirectos en los procesos informativos contribuyó a diluir la idea de una vocación martirial en Juan de Ávila. La historia crítica, representada por Sala Balust, omite cualquier alusión a este deseo de ser mártir $^{28}$. Tampoco encontramos ninguna referencia biográfica, sino más

\footnotetext{
${ }^{22}$ Proceso en Jaén, 669.

${ }^{23}$ Proceso en Baeza, 730; el testimonio del licenciado Alonso Díaz Reies Carleval, presbítero, se apoya en lo que oyó decir a su tío, "que el dicho siervo de Dios quería pasar a las Indias a convertir Almas con deseo de ser mártir de Christo nuestro Señor". También dice haberlo oído del doctor Carleval otro clérigo, Bartolomé Gutiérrez Serrano (p. 757).

${ }^{24}$ Ibid., 746. Se apoya en ellos el bachiller Bernardino de Rus Calatrava, presbítero (p. 747).

${ }^{25}$ Proceso en Andújar, 888.

${ }^{26}$ Fray Luis de Granada, Vida del Padre Maestro Juan de Ávila y las partes que ha de tener un predicador del Evangelio, en Fray Luis de Granada y Licenciado Luis Muñoz, Vidas del Padre Maestro Juan de Ávila, ed. Luis Sala Balust (Barcelona: Juan Flors, 1964), 102. Sobre esta Vida, María Jesús Fernández Cordero, Juan de Ávila, XIX-XXXI.

${ }^{27}$ Licenciado Luis Muñoz, Vida y virtudes del venerable varón el P. Maestro Juan de Ávila, predicador apostólico, en Fray Luis de Granada y Licenciado Luis Muñoz, Vidas..., 168. Sobre esta Vida, María Jesús Fernández Cordero, Juan de Ávila, XXXI-XLII.

${ }^{28}$ Luis Sala Balust y Francisco Martín Hernández, "Estudio biográfico”, en San Juan de Ávila, OC $\mathrm{I}, 31$.
} 
Vestir la librea de CRISto. Huellas de espiritualidad martirial en San Juan...

bien una breve compilación temática, en la voz correspondiente del Diccionario avilista elaborado por Esquerda Bifet ${ }^{29}$. Solo a raíz de las recientes beatificaciones de mártires en España, Santiago Bohigues ha señalado la existencia de tal vocación en el Maestro, pero la trata más como una referencia para la actualidad que como un objeto de estudio específicamente avilista ${ }^{30}$.

Ahora bien, el hecho de que no se pueda documentar de modo directo el deseo de ser mártir por el que preguntaban los interrogatorios ¿significa la ausencia de una espiritualidad martirial en Juan de Ávila, o es posible rastrearla como una dimensión de su espiritualidad cristocéntrica y sacerdotal? De ser así, ¿cuál sería su origen experiencial? ¿qué pensó del martirio? ¿existieron para él actitudes o disposiciones que se identificaran de alguna manera con la fidelidad de los mártires y moldearan la espiritualidad en este sentido? Intentaremos responder a estas preguntas acercándonos, en primer lugar, al episodio que configuró su experiencia en una línea pascual: el paso por la cárcel inquisitorial de Sevilla; exploraremos luego el contenido de sus enseñanzas sobre el martirio; y, por último, veremos en su epistolario cómo orientó las actitudes de sus discípulos o personas a quienes acompañaba hacia una dinámica de entrega martirial en el camino de la vida.

\section{La experiencia de persecución, configuradora de una espiritualidad martirial}

\subsection{Algunos indicios en torno al proceso inquisitorial}

El acontecimiento del proceso inquisitorial de Juan de Ávila entre 1531 y 1533 es reconocido actualmente como uno de los más decisivos en el decurso de su vida. Díaz Lorite se ha referido a él como "la auténtica escuela de su formación: la cárcel de Sevilla", y como algo que "marcará toda su trayectoria personal y ministerial", al consistir en "la experiencia del amor de Dios manifestado en Jesucristo crucificado"31. Martínez Millán entiende que "sin duda

\footnotetext{
${ }^{29}$ Juan Esquerda Bifet, "Martirio", en Diccionario de San Juan de Ávila (Burgos: Monte Carmelo 1999), 601-605.

${ }^{30}$ Santiago Bohigues Fernández, "San Juan de Ávila y su vocación martirial", Burgense 56/1 (2015): 255-272. En la nota 1 indica: "Dicho en la Iglesia de la Encarnación -Basílica de San Juan de Ávila- en Montilla (Córdoba), 7 de mayo de 2014". En realidad, solo dedica al tema en Juan de Ávila las pp. 269-272, pues los anteriores apartados versan sobre la vocación al martirio de todo cristiano, la espiritualidad martirial en los primeros tiempos del cristianismo y en los actuales, todo ello entreverado con citas del Maestro.

${ }^{31}$ F. Javier Díaz Lorite, Experiencia del amor de Dios y plenitud del hombre en San Juan de Ávila (Madrid: 2007), 68.
} 


\section{María Jesús Fernández Cordero}

ninguna, el episodio que vivió con su detención por parte de la inquisición, le marcó y le hizo estallar todas sus inquietudes espirituales que llevaba dentro"; su expresión sería el Audi, filia ${ }^{32}$. Pulido Serrano, que lo ha estudiado desde la clave conversa, considera que "la experiencia carcelaria tuvo un valor catártico cuyo resultado quedó expresado en sus obras"33. Podemos afirmar que lo que se produjo fue "una configuración pascual de su espiritualidad", que se puede describir como "la adquisición de una particular sabiduría de la Cruz, inherente al conocimiento interno de Cristo, y experimentada como proceso de redención"34.

Pues bien, el lenguaje martirial aparece en el proceso como algo atribuido a Juan de Ávila por parte de los acusadores y fundamenta la grave sospecha de que mantiene una actitud de oposición al Santo Oficio. En los cargos, Leonor Gómez de Montesino "depuso que, confesándose con el siervo de Dios, la había preguntado si tenía odio a los confesos en el Santo Tribunal; y habíendole ella respondido que sí, el siervo de Dios replicó que muchos de los que eran quemados eran mártires; y que fuese su alma como la de ellos" ${ }^{\prime 35}$. Esta idea de que muchos de los ejecutados eran mártires era "un topos clásico de la espiritualidad conversa" ${ }^{36}$. En su defensa, Ávila no negó haber actuado así ni haber afirmado tal cosa, sino que matizó la afirmación, explicó sus motivos y fundamentó su criterio:

Respondió el siervo de Dios que, algunas veces, predicando y en pláticas particulares, había dicho que los que con paciencia sufrían la muerte que les daba la justicia, si morían con fe y en gracia, podía aquella pena serles como martirio; y que tan grande podía ser la pena por ellos sufrida, y su arrepentimiento, que de la horca volaran al cielo. Y que habrá dicho lo mismo de los sentenciados por el Santo Oficio; y esto, para inducir a los condenados a tener paciencia y no tener odio a los jueces.

Probó en la defensa el siervo de Dios que, hablando de los condenados por el Tribunal de la Inquisición, solía decir que algunos de ellos podían tener tanta contrición de sus pecados y tanta paciencia, que del patíbulo volaran al cielo ${ }^{37}$.

\footnotetext{
${ }^{32}$ José Martínez Millán, "Cambios en la espiritualidad de Juan de Ávila”, en Juan de Ávila, unicus..., 141.

${ }^{33}$ Juan Ignacio Pulido Serrano, "Experiencia vital y elaboración de una fórmula conciliadora en la obra de Juan de Ávila", en El Maestro Juan de Ávila (1500?-1569). Un exponente..., 175.

${ }^{34}$ Fernández Cordero, Juan de Ávila..., 150.

${ }^{35}$ Camilo M ${ }^{\text {a }}$ Abad, "El proceso de la Inquisición contra el beato Juan de Ávila. Estudio crítico a la luz de documentos desconocidos", Miscelánea Comillas 6 (1946): 114-115.

${ }^{36}$ Stefania Pastore, Una herejía española. Conversos, alumbrados e Inquisición (1449-1559) (Madrid: Marcial Pons, 2010), 335.

${ }^{37}$ Abad, "El proceso de la Inquisición”, 115.
} 
Si la acusación consistía en haber dicho que "los que eran quemados eran mártires", en su defensa Ávila matiza y pasa a una comparación: "podía aquella pena serles como martirio". Ávila insiste en que ha expuesto los requisitos para que esto sea así: la paciencia, la fe, la gracia, el arrepentimiento y no odiar. El punto de comparación con el martirio radica en el efecto salvífico de asumir la ejecución en gracia y desde tales actitudes: ese efecto es la entrada directa en el cielo, algo que la tradición de la Iglesia asocia a la muerte martirial desde los primeros tiempos del cristianismo ${ }^{38}$.

Podemos suponer que, si Ávila se mantuvo en esta idea, él mismo se identificaría con ella durante su estancia en prisión, como reo y ante la incertidumbre de la pena que podría recaer sobre él. Seguramente cultivó las actitudes que él mismo aconsejaba a los condenados a quienes había acompañado. Fr. Luis de Granada narra este episodio de su vida al tratar de la paciencia en las injurias y subraya que "estaba muy confiado en Dios y en su inocencia"; recoge la promesa del Señor al justo: "Con él estoy en la tribulación: librarlo he y glorificarlo he" [Sal 91 (90),15]; testimonia el perdón y el amor a los enemigos cuando, al predicar tras salir de la cárcel, Ávila exhortó a los oyentes a orar por los que le habían calumniado ${ }^{39}$. El licenciado Muñoz amplificó esta narración y, al subrayar su confianza en Dios, introdujo algunos elementos tomados de los procesos informativos para la beatificación; según él, uno de los jueces le habría dicho: "su negocio está en las manos de Dios", queriendo advertirle con ello que "estaba en muy peligroso estado"; su respuesta habría sido: "Nunca ha tenido mi negocio mejor estado; hasta aquí han hecho los hombres, ahora hará Dios" ${ }^{40}$. Esta sería la línea de lo testimoniado en Baeza por Alonso Díaz Reyes, sobrino del doctor Carleval, quien, apoyándose esta vez en los recuerdos de su padre, contó que los inquisidores anunciaron a Ávila que "havían de sentenciarlo a muerte y que estava publicado auto para ello dentro de tres días" ${ }^{41}$; la resolución final del caso quedó envuelta en lo milagroso: una misa celebrada por él en la cárcel, en la que su figura quedó cercada de luz, y una misteriosa carta de los acusadores entre sí que llegó providencialmente a manos de los inquisidores dejando al descubierto una conjura. Aun teniendo en cuenta la amplificación hagiográfica y la tendencia a lo maravilloso y a lo dramático en estas fuentes, lo que se ha transmitido de este

\footnotetext{
${ }^{38}$ Willy Rordorf, "Theólogie et spiritualité du martyre", en "Martyre", Dictionnaire de spiritualité, ascétique et mistique, t. X (Paris: Beauchesne, 1980), col. 726. (en adelante DSp). La convicción de que el mártir irá directamente al paraíso se apoya en Lc 23,43 (las palabras de Jesús en la cruz dirigidas a uno de los malhechores: "hoy estarás conmigo en el Paraíso") y se constata desde Tertuliano, Orígenes y Cipriano.

${ }^{39}$ Granada, Vida, 93-94.

${ }^{40}$ Muñoz, Vida, 176.

${ }^{41}$ Proceso en Baeza, 735-736.
} 


\section{María Jesús Fernández Cordero}

episodio incide en la actitud de fe y confianza por parte de Ávila al atravesar una situación de peligro cuyo alcance real y temor subjetivo se nos escapan ${ }^{42}$.

En cambio, por su coherencia con los escritos de Ávila, sí podemos afirmar la veracidad de las palabras de Fr. Luis de Granada -las más conocidas de la Vida del Maestro que él escribió- al sintetizar su paso por la cárcel como experiencia de gracia:

Y así, tratando una vez familiarmente conmigo de esta materia, me dijo que en este tiempo le hizo Nuestro Señor una merced que él estimaba en gran precio, que fue darle un muy particular conocimiento del misterio de Cristo; esto es, de la grandeza de esta gracia de nuestra redención, y de los grandes tesoros que tenemos en Cristo para esperar, y grandes motivos para amar, y grandes motivos para alegrarnos en Dios y padecer trabajos alegremente por su amor. Y por eso tenía él por dichosa aquella prisión, pues por ella aprendió en pocos días más que en todos los años de su estudio. En lo cual vemos haber hecho Nuestro Señor con este su siervo una gracia muy semejante a la que hizo al profeta Hieremías. Porque estando, por la verdad que predicaba, preso, lo consoló Nuestro Señor en la cárcel con un gloriosísima y muy alegre revelación, diciéndole: Llámame y oírte he, y revelarte he muy grandes y verdaderos misterios que tú no sabes (Jer 33,3).43

Por lo general, la historiografía resalta, desde este texto, el "particular conocimiento del misterio de Cristo" que le fue otorgado a Ávila en "aquella prisión", conocimiento o merced que le permite valorar el acontecimiento desde una mirada diferente. Ahora bien, ¿podríamos identificar de alguna manera que también en la cárcel se forjó una espiritualidad martirial? Podemos explorarlo a través de las cartas que han sido relacionadas más directamente con esta experiencia o con alguna otra de persecución intensa, en las que el Maestro deja traslucir una mística abierta a un horizonte de este tipo.

\subsection{Una metáfora martirial: vestir "la librea de Cristo"}

Sobre la Carta 58, dirigida a unos sus devotos afligidos por una persecución que se había levantado ${ }^{44}$, ha predominado en la historiografía la hipótesis de que fuera escrita en prisión o en un contexto muy cercano a ella, aunque también se ha apuntado la posibilidad de que dicha persecución fuera la que afectó más directamente a sus discípulos en los años 1549-1552 ${ }^{45}$. En todo

\footnotetext{
${ }^{42}$ Para comprender el proceso teniendo en cuenta el contexto, la composición del jurado y el sentido de la sentencia, Fernández Cordero, Juan de Ávila..., 113-151.

${ }^{43}$ Granada, Vida, 94-95.

${ }^{44}$ Carta 58, OC IV, 268-271.

45 Sala Balust y Martín Hernández la sitúan en prisión, hacia 1532, en el "Estudio biográfico",
} 
caso, es el escrito que nos permite asomarnos con mayor profundidad a la vivencia del propio Ávila en los padecimientos por causa de Cristo y su evangelio. Sin entrar en la totalidad de esta temática ${ }^{46}$, nos interesa ahora señalar la presencia en ella de dos contenidos que remiten a la idea de martirio.

El primero de ellos es la referencia a San Pablo como modelo de apóstol dispuesto a sufrir por Cristo. La carta comienza con una larga cita de 2 Cor 1,3-5, que sitúa todo el escrito como orientado a la consolación que viene de Dios y que él desea transmitir. Pero enlaza luego con el recuerdo de los azotes y golpes que el propio Pablo menciona en 2 Cor 11,25, hasta culminar en la cita de 2 Cor 4,11, romanceada así: "en otra parte dice, nosotros siempre somos traídos a la muerte por amor de Jesucristo, porque la vida de Jesucristo sea manifiesta en vosotros" ${ }^{47}$. Con ese "siempre" Ávila traduce bien el sentido del texto paulino, que se refiere a una entrega a la muerte "mientras aún vivimos", que se realiza "de continuo durante toda la vida" y es motivada por causa de Jesús en el servicio a la misión ${ }^{48}$. Las actitudes que atribuye al apóstol sirven para contrastar las de los discípulos avilistas y suponen el descubrimiento de la "merced" divina que se encierra en la persecución:

Y con todas estas tribulaciones [Pablo] no sólo no murmura ni se queja de Dios, como los flacos suelen hacer; no se entristece, como los amadores de su honra o regalo; no importuna a Dios que se las quite, como los que no las conocen, y por eso no las quieren por compañeras; no las tiene por pequeña merced, como los que las desean poco; mas toda la ignorancia y flaqueza dejada atrás, bendice en ellas y da gracias por ellas al Dador de ellas como por una señalada merced, teniéndose por dichoso de padecer algo por la honra de Aquel que sufrió tantas deshonras por sacarnos de la deshonra en que estábamos sirviendo a la vileza de los pecados, y nos hermoseó y honró con su espíritu y adopción de hijos de Dios, y nos dio arra y prenda de gozar en el cielo de Él y por É ${ }^{49}$.

Esta disposición a una entrega a la muerte a lo largo de la vida es expresada luego como un auténtico deseo de Ávila en la oración a Jesús Nazareno que inserta en esta carta. De esta verdadera joya de la literatura espiritual, que revela una mística del encuentro con Cristo en la cruz como lugar de reden-

38-39, y en la edición (OC IV, 268). También Díaz Lorite, Experiencia del amor de Dios..., 76-78. La segunda hipótesis fue sostenida por Marcel Bataillon, "Jean d'Avila retrouvé (A propos des publications récentes de D. Luis Sala Balust)", Bulletin Hispanique 57/1-2 (1955): 10.

${ }^{46}$ Fernández Cordero, Juan de Ávila..., 140-147.

${ }^{47}$ Carta 58, OC IV, 268. La traducción del v. 11 en la Biblia de Jerusalén es la siguiente: "Pues, aunque vivimos, nos vemos continuamente entregados a la muerte por causa de Jesús, a fin de que también la vida de Jesús se manifieste en nuestra carne mortal". Ávila lo ha fundido con el v. 12: "De modo que la muerte actúa en nosotros, mas en vosotros la vida".

${ }^{48}$ Senén Vidal, Las cartas originales de Pablo (Madrid: Trotta, 1996), 234, n. 30.

${ }^{49}$ Carta 58, OC IV, 268. 


\section{María Jesús Fernández Cordero}

ción, nos interesa rescatar la metáfora de la librea. Tras haber manifestado la hondura de la liberación recibida por la cruz de Cristo, pero también la "vergüenza" y el "dolor" por la desproporción entre el don recibido y su respuesta -"porque siendo de ti tan amado, lo cual muestran tus tantos tormentos, yo te amo tan poco como parece en los pocos míos" ${ }^{50}$-, contrasta su vestidura y la de Cristo crucificado con esta imagen:

Dime, ¿por qué quieres que sea pregonero tuyo y alférez que lleva la seña de tu Evangelio, y no me vistes de pies a cabeza de tu librea? ¡Oh cuán mal me parece nombre de siervo tuyo, y andar desnudo de lo que tú tan siempre, y tan dentro de ti, y tan abundantemente anduviste vestido! Dinos, ;oh amado Jesús!, por tu dulce cruz, ¿hubo algún día que aquesta ropa te desnudases, tomando descanso? ¿O fuete algún día esta túnica blanda, que tanto a raíz de tus carnes anduvo, decir: Triste es mi ánima hasta la muerte? ¡Oh, que no descansaste, porque nunca nos dejaste de amar, y esto te hacía siempre padecer! Y cuando te desnudaron la ropa de fuera, te cortaron en la cruz, como encima de mesa, otra ropa bien larga dende pies a la cabeza, y cuerpo y manos, no habiendo en ti cosa que no estuviese teñida con tu benditísima sangre, hecho carmesí resplandeciente y precioso: la cabeza con espinas, la faz con bofetadas, las manos con un par de clavos, los pies con uno muy cruel para ti y para nosotros dulce; y lo demás del cuerpo con tantos azotes, que no sea cosa ligera de los contar. Quien mirando a ti, amare a sí y no a ti, grande injuria te hace. Quien, viéndote tal, huyere de lo que a ti lo conforma, que es el padecer, no te debe perfectamente amar, pues no quiere ser a ti semejable ${ }^{51}$.

La librea era la vestidura que identificaba al servidor con su rey o señor ${ }^{52}$. Aquí Ávila la atribuye al pregonero que lleva el mensaje o al alférez que porta la bandera de su señor, creando así un conjunto alegórico, de reminiscencias caballerescas, para referirse al ministerio del predicador. El juego de desnudez y vestidura en relación con Jesús le conduce luego al recuerdo de Getsemaní:

\footnotetext{
${ }^{50}$ Carta 58, OC IV, 269.

${ }^{51} \mathrm{Ib} ., 269-270$.

${ }^{52}$ El Diccionario de autoridades, IV, ed. 1734, la define así: "El vestuario uniforme que los Reyes, Grandes, Títulos y Caballeros dan respectivamente a sus Guardias, Pages, y a los criados de escalera abaxo, el qual debe ser de los colores de las armas de quien le da. Suelese hacer bordada, o guarnecida con franjas de varias labores. Covarrubias dice se llamó Librea, por los muchos privilegios y libertades que gozan los que sirven a los Reyes". Aunque en su origen medieval la librea se refería a dones diversos que expresaban la liberalidad del señor, el término acabó por referirse a vestimentas distribuidas de modo ordinario o extraordinario; a partir del siglo XIV, adquirieron un significado emblemático, portando divisas y colores que expresaban el compartir del príncipe o del señor con un grupo escogido de cortesanos o servidores próximos; el siglo XV fue el de su mayor apogeo, y luego el contenido emblemático se desvió hacia las joyas, collares o broches. Laurent Hablot, "Le double du prince. Les livrées emblématisées à la cour, un outil politique reflet d'une nouvelle conception du pouvoir", en La cour du prince, ed. Jacques Paviot et al. (Paris: Honoré Champion, 2011), 281-299.
} 
al mencionar las palabras sobre la tristeza de su alma (Mt 26,38; Mc 14,34), la "túnica" a la que ha aludido asume la evocación del sudor de sangre (Lc 22,44 ) aun sin citarlo. El punto culminante es la contemplación del cuerpo de Cristo tendido en la cruz, un "carmesí resplandeciente y precioso". Carmesí, que procede del árabe (qarmazí), es utilizado aquí como sustantivo; en este caso, tiene dos acepciones: polvo de color de la grana (colorante) del quermes, o tela de seda roja ${ }^{53}$. Creemos que Ávila fusiona ambos significados: está hablando de una "ropa" -cortada sobre la cruz- que cubre todo el cuerpo de Jesús y queda "teñida" con su "benditísima sangre". La sangre es a la vez la grana que tiñe de color carmesí y la ropa o tela teñida que cubre todo el cuerpo. Pero, finalmente, es el mismo Jesús, su carne, su cuerpo crucificado, el que acaba "hecho carmesî". Este es calificado como "resplandeciente y precioso", términos apropiados a la valoración social que efectivamente tenían estas telas ${ }^{54}$.

En el mundo cortesano, los tonos rojos de las libreas eran signo de distinción y se reservaban a los oficiales de mayor rango y la nobleza más próxima al rey en las celebraciones de importancia ${ }^{55}$. En el ámbito litúrgico, el significado simbólico de los colores había quedado fijado desde el siglo XII; como ha señalado Michel Pastoureau, la mayor parte de los tratadistas entendieron que el rojo evocaba "le sang versé par et pour le Christ, la Passion, le martyre, le sacrifice et l'amour divin (passio, compassio, oblatio passionis, crucis signum, effusio sanguinis, caritas, misericordia)" ${ }^{56}$. El uso en las vestimentas litúrgicas fue unificándose gracias a la influencia del tratado sobre la misa $D e$ sacro sancti altaris mysterio, de Lotario Conti de Segni, luego papa Inocencio III: aquí el color rojo aparecía establecido, en los usos romanos, para las fiestas de los apóstoles y de los mártires, de la Santa Cruz y de Pentecostés; fue entonces cuando el rojo sustituyó al blanco (color del paraíso) en las fiestas de los mártires, precisamente por su capacidad para simbolizar la sangre derramada por Cristo ${ }^{57}$. El siglo XIII, con la difusión de la heráldica, moldeó notablemente la sensibilidad cromática de Occidente y, a final de esa centuria, fueron las vestimentas las que se tiñeron de colores, distinguiéndose las de los distintos estratos sociales no por el color, sino por la calidad de la tintura (brillante en los superiores, apagada en los inferiores). La librea que se distribuía

\footnotetext{
${ }^{53}$ RAE, "Carmesî", Diccionario de la lengua española.

${ }^{54}$ Amy Butler Greenfield, Un rojo perfecto. Imperio, espionaje y búsqueda del color del deseo (Valencia: Universitat de València, 2010).

${ }^{55}$ Germán Gamero Igea, "Las libreas en el séquito de Fernando el Católico: relaciones y representaciones de los poderes cortesanos", Studia histórica. Historia Medieval 36/1 (2018): 161-194.

${ }^{56}$ Michel Pastoureau, "Le temps mis en couleurs: des couleurs liturgiques aux modes vestimentaires (XIIe-XIIIe siècles), Bibliothèque de l'École des chartes, 157/1 (1999): 115.

${ }^{57}$ Ibid., $117-118$.
} 


\section{María Jesús Fernández Cordero}

anualmente en las cortes jugó entonces el papel de difusión de los colores del rey $^{58}$.

Todos estos elementos nos permiten comprender el simbolismo del texto avilista. Habría que añadir, sin duda, la imagen paulina del revestirse de Cristo (Rom 13,14; Gál 3,27). Pero nos interesa subrayar ahora la dimensión martirial que contiene la metáfora de esta librea carmesí. Antes que Juan de Ávila, Francisco de Osuna la había empleado con el mismo sentido de identificación entre el cristiano y Cristo.

En efecto, Osuna utilizó el lenguaje emblemático medieval en su obra Ley de amor, perteneciente a su etapa sevillana, impresa en $1530^{59}$. Al hablar del amor a los enemigos en el c. 40, citaba el mandamiento de Jesús en Lc 6,2728 y lo presentaba como el elemento distintivo del evangelio con respecto a la ley veterotestamentaria:

Cristo dice: A vosotros que oís digo: Amad a vuestros enemigos, haced bien a los que os aborrecieron, bendecid a los que os maldicen y orad por vuestros calumniadores. Esta sentencia se repite muchas veces en el Evangelio, porque es devisa suya; ésta es la librea y armas en que el Evangelio difiere de la Vieja Ley, que no tenía tanto calor de caridad, porque era vieja, y en los viejos no hay tanto calor como en los nuevos ${ }^{60}$.

El origen e intencionalidad de estas figuras literarias aparece con toda claridad:

Los señores y las religiones, y los linajes, y las ciudades, y todas las cosas estimadas, suelen hacer mucho caso de aquello en que son señalados entre los otros, y preciarse de ello, y publicarlo, y pintarlo en muchas partes, tomándolo por armas y sobreseñal para que sean entre todos conocidos ${ }^{61}$.

Al afirmar que el amor a los enemigos es "la cosa en que más singularmente defiere la ley de Cristo de la ley natural y de la escrita", Osuna lo presentaba como signo de identidad del cristiano: "la devisa que Cristo da a los suyos y sus armas y sobreseñal o librea es el amor de los enemigos"; abrazarlo y seguirlo era poseer el distintivo para ser tenido por tal; por el contrario -decía dirigiéndose al lector-, "cuando quieres mal a tu enemigo, perdéis ambos la librea de Cristo y no merecéis ser dichos cristianos, pues que

\footnotetext{
${ }^{58}$ Ibid., 131.

${ }^{59}$ Citamos por Fray Francisco de Osuna, Ley de amor santo, en Místicos franciscanos españoles $\mathrm{t}$. I, ed. de Fr. Juan Bautista Gomis (Madrid: BAC, 1948), 221-700.

${ }^{60} \mathrm{Ibid}$., 581; la cursiva en la ed. cit. El contraste entre lo viejo y lo nuevo en este texto puede relacionarse con la defensa de los cristianos nuevos por parte de Osuna, si bien no lo explicita.

${ }^{61}$ Id.
} 
dejáis sus armas" ${ }^{2}$. Según los estudiosos de la heráldica, mientras las armas identificaban al linaje, las divisas o lemas eran expresión del individuo y, en el siglo $\mathrm{XV}$, creaban un lazo más personalizado y afectivo que el propiamente feudal; en esta centuria, además, el término librea fue sinónimo de emblema y de divisa ${ }^{63}$.

Para Osuna, por tanto, el amor a los enemigos identificaba al cristiano con Cristo, en el doble sentido de pertenencia y semejanza. Más aún, como en el caso de los linajes, suponía una vinculación de familia: "Mira, pues, hermano, que te vistió Cristo de su librea y te manda lo que él mesmo hizo para que seas hermano suyo e hijo de su Padre" 64 .

No obstante, y no sin cierta contradicción, el amor a los enemigos suponía la ley de amor para "el que quiere ser muy perfecto", y el franciscano admitía la doctrina clásica de una gradación hasta llegar a esa perfección. Pues bien, en el c. 48 de la misma obra, en que establecía los grados del amor y les asignaba en correspondencia su representación en el templo de Salomón, entendía que en el amor al prójimo la perfección era el grado sumo del amor a los enemigos, mientras que, en el amor de Dios, la perfección consistía en ejercitarse "en solo amor" ${ }^{65}$. Este grado sumo de perfección en la caridad estaba representado en el sancta sanctorum, donde la sangre que introduce el sumo sacerdote una vez al año para ofrecer delante del propiciatorio "es la sangre del martirio, que pertenece a los perfectos, que desean morir y pasar por martirio a Cristo, lo cual es ofrecerle una vez su sangre" ${ }^{\prime 66}$. Matizaba el autor que todo cristiano, en cualquier grado de amor de Dios y sin haber llegado a la perfección, estaba obligado a aceptar el martirio si la alternativa era perder la fe; esto sería un caso de necesidad, mientras que "a los perfectos amadores conviene ofrecerse a la muerte por alabar al que aman, aunque de ello no haya necesidad" 67 .

\footnotetext{
${ }^{62}$ Ibid., 582.

${ }^{63}$ Laurent Hablot, "Le double du prince, 281-282.

${ }^{64}$ Osuna, Ley de amor santo, 582.

${ }^{65}$ Ibid., 657.

${ }^{66}$ Ibid., 658-659.

${ }^{67}$ Ibid., 659. Añadía: "Esta segunda manera de martirio, que conviene a los perfectos amadores, se figura en la sangre que el sumo sacerdote llevaba a ofrecer a lo más adentro del templo, así como en la que los menores sacerdotes ofrecían en el patio se figuraba la primera manera de martirio, que conviene a todo amador de Dios, por el cual debemos antes perder la vida que su amor". Osuna parece excederse al hablar de este segundo martirio de los perfectos, pues la Iglesia desde el principio ha apartado al cristiano de buscar positivamente el martirio, y el ofrecerse sin necesidad parece no estar lejos de eso. Santo Tomás hablaba de la necesidad del martirio en orden a la propia salvación, y reconocía que "hay casos en que sufrir el martirio no es necesario para la salvación, como leemos muchas veces que los santos mártires, llevados del celo de la fe y de la caridad fraterna, se entregaron voluntariamente al martirio" (Summa theol, II-II, q. 124, a. 3 ad. 1). Esta línea tomista estaría en la base de las palabras de Osuna.
} 


\section{María Jesús Fernández Cordero}

En el precedente de Francisco de Osuna encontramos, por tanto, la metáfora de la librea como expresiva de la identidad del cristiano y de su pertenencia a Cristo y su semejanza con él. En su obra es posible establecer la relación entre librea - amor a los enemigos - perfección en la caridad - martirio. Al quedar identificada con el amor a los enemigos, la librea se viste en situaciones de persecución, de padecimiento de injurias y, en caso extremo, de riesgo de la vida y martirio por causa del evangelio.

Podemos entender, pues, que el fragmento de la oración a Jesús nazareno que Juan de Ávila inserta en la carta 58 se nutre de una tradición cultural bajomedieval y quizás de un precedente cercano, Osuna. A su vez, su escrito, de mayor intensidad mística y cristocéntrica, visualiza, a través del color carmesí de la ropa y del cuerpo de Jesús, el carácter martirial de la librea que Ávila ansiaba vestir. Aquí sí podríamos hablar de un deseo de ser mártir, expresado en forma oracional, mística y poética, testimoniado casi sin querer por el propio Ávila en una situación concreta de persecución. Pero no se trata de un ideal a alcanzar, sino de un deseo de correspondencia al amor recibido.

\subsection{El deseo del martirio: redamatio y mística}

Profundicemos un poco en este sentido de correspondencia desde otro texto avilista. El Tratado del amor de $\operatorname{Dios}^{68}$ se rige todo él por la contemplación de la iniciativa y primacía del amor de Dios, desde sus primeras palabras: "La causa que más mueve el corazón al amor de Dios es considerar profundamente el amor que nos tuvo Él, y, con Él, su Hijo benditísimo, nuestro Señor" ${ }^{69}$. Uno de los muchos valores de este texto consiste en que sitúa en la humanidad de Cristo la redamatio ${ }^{70}$, es decir, la respuesta agradecida de Jesús a todas las gracias que la Santísima Trinidad le había concedido. Por tanto, encontramos aquí -en la humanidad de Cristo- el "arquetipo y ejemplar de todo amor agradecido a Dios" ${ }^{\prime 1}$. Ahora bien, en Jesús este amor, que está hecho -como en todo ser humano- de deseos y de escucha de la voluntad de Dios, ha de retornar al Padre en una respuesta de amor muy concreta, descubierta en el intercambio de miradas y el diálogo con Él: "tomar sobre sí esta obra de la redempción de los hombres", con un amor

\footnotetext{
${ }^{68}$ En OC I, 951-974. Pedro L. Vives Pérez, "Lectura cristológica del Tratado del amor de Dios de San Juan de Ávila", Burgense 52/2 (2011): 375-400; califica este escrito como "una síntesis sapiencial de todos los temas teológicos avilistas" (377).

${ }^{69}$ Ávila, Tratado del amor de Dios, 1, OC I, 951.

${ }^{70}$ María Jesús Fernández Cordero, “«Dar el corazón a Dios». La redamatio en San Juan de Ávila”, en San Juan de Ávila, Doctor de la Iglesia. Actas del Congreso Internacional, ed. Juan Aranda Doncel y Antonio Llamas Vela (Córdoba: Diputación de Córdoba, 2013), 427-461.

${ }^{71}$ Ibid., 450.
} 
hacia ellos tal que estuviese dispuesto a "hacer y padecer todo lo que para esto fuese necesario"72.

En esta relación de amor entre el Padre y el Hijo sitúa Ávila el origen del deseo de padecer de Cristo. Un deseo que también los santos vivieron como redamatio: "padecer por amor de Dios"; pero mucho más grande en Cristo, que es el "Santo de los santos". Aquí alude Ávila al deseo del martirio en Santo Domingo, el apóstol San Andrés y sobre todo San Pablo ${ }^{73}$. Pero en Jesús se trata del deseo de un "bautismo" (Lc 12,50) y de una "hora" (lenguaje joánico) que se identifican con la cruz. Y he aquí el vocabulario de la vestidura de sangre:

Hasta que se llegue la hora, vives, Señor, en estrechura; porque era tan grande el deseo de verte teñido en tu sangre por nosotros, que cada hora que esto se dilataba te parecía mil años, por la grandeza de tu amor ${ }^{74}$.

Hay una teología esponsal, con ecos del Audi, filia (la alegría del corazón de Cristo, el tálamo de la cruz), para subrayar que es el amor el que le hizo "estar desnudo y colgado de una cruz, hecho escarnio del mundo", y morir ${ }^{75}$.

Mirar a Cristo en la cruz, y descubrir en su interioridad un amor aún más grande que el que mostraban sus llagas ${ }^{76}$, es lo que despierta los mismos deseos en quienes son su "verdaderos hijos y amigos":

Esto es lo que los hace salir de sí y quedar atónitos cuando, recogidos en lo secreto de su corazón, les descubres estos secretos y se los das a sentir. De aquí nace el deshacerse y abrasarse sus entrañas, de aquí el desear los martirios, de aquí el holgarse en las tribulaciones (cf. Col 1,24), de aquí el sentir refrigerio en las parrillas y el pasearse sobre las brasas como sobre rosas, de aquí el desear los tormentos como convites, y alegrarse de lo que todo el mundo teme, y abrazar lo que el mundo aborrece, y buscar abominaciones de Egipto para sacrificarlas a Dios (cf. Vg. Ex 8,26) ${ }^{77}$.

El sentido paradójico de este deseo de martirio y de este gozo en el sufrimiento se debe a que es el correlato de la contemplación de la pasión como anhelo de Cristo, del viernes santo como día de la alegría de su corazón y de la cruz como tálamo del desposorio, perspectiva muy arraigada en Ávila y que tiene su mayor expresión en la famosa exposición sobre Cant 3,11 en el

\footnotetext{
72 Ávila, Tratado del amor de Dios, 6, OC I, 959.

${ }^{73}$ Ibid., n. 8, 963-965.

${ }^{74}$ Ibid., n. 8, 965.

${ }^{75}$ Ibid., n. 8, 967.

${ }^{76}$ Ibid., n. 7, 962: "mucho más amó que padeció; muy mayor amor le quedaba encerrado en las entrañas de lo que nos mostró acá de fuera en sus llagas".

${ }^{77}$ Ibid., n. 9, 967-968.
} 


\section{María Jesús Fernández Cordero}

Audi, filia ${ }^{78}$. En este núcleo cristológico se han de comprender estas antítesis. En cuanto a su formulación, esta retórica avilista parece más vinculada a la tradición literaria y artística medieval -que empleó el contraste entre la serenidad, fortaleza y alegría de los mártires (dulzura, sonrisa, oración...) y la ira, violencia y rabia de sus verdugos- que a la crudeza con que la cultura martirial de fines del XVI y el XVII representaría estas escenas ${ }^{79}$. Está también en armonía con la tradición de los primeros siglos, de los Santos Padres que dejaron constancia de este deseo y este "regocijo" humanamente incomprensible $^{80}$. Pero toma luego un estilo personal y lírico que hace de las páginas siguientes uno de los mejores ejemplos de la mística avilista; de nuevo este movimiento es retorno de amor, redamatio: "¿cómo te pagaré, Amado mío, este amor?". Recordando la sangre que Moisés, en ratificación de la alianza, derramó sobre el altar y sobre el pueblo (cf. Ex 24,5-8), él quiere incluirse en este último recibiendo sobre sí la sangre de Cristo: "véame yo con esa sangre teñido y con esa cruz enclavado". Intenso deseo de participación y hasta de suplencia en la cruz de Cristo:

¡Oh cruz!, hazme lugar, y véame yo recibido mi cuerpo por ti y deja el de mi Señor. ¡Ensánchate, corona, para que pueda yo poner ahí mi cabeza! ¡Dejad, clavos, esas manos inocentes y atravesad mi corazón y llagadlo de compasión y de amor! ${ }^{81}$

El autor pasa de contemplar el amor de Cristo en la cruz a descubrir sus efectos en su propia interioridad, de tal modo que lo que eran referencias a los mártires y al deseo de martirio se convierte en experiencia mística. Tras varias referencias bíblicas al fuego del amor divino, prorrumpe en exclamaciones: “¡Oh dulce fuego! ¡Oh dulce amor! ¡Oh dulce llama! ¡Oh dulce llaga, que ansí enciendes los corazones helados más que nieve y los conviertes en amor $!^{12}$. La cruz se convierte en "una espiritual ballesta" en la que está tendido el cuerpo de Cristo, que desde su costado lanza una "saeta de amor" para "herir el corazón desarmado" $"$.

\footnotetext{
${ }^{78}$ Ávila, Audi, filia [I], II, n. 60-64, OC I, 468-471.

${ }^{79}$ Basta contrastar el estudio de Brigit G. Ferguson, "The Pleasure of Martyrdom", Mirabilia 18 (2014): 116-136, y las páginas dedicadas al martirio en la obra clásica de Emile Mâle, El arte religioso de la Contrarreforma. Estudios sobre la iconografía del final del siglo XVI y de los siglos XVII y XVIII (Madrid: Encuentro, 2001), 113-150.

${ }^{80}$ Juan B. Valero, "Martirio y libertad en la primitiva Iglesia", Communio 9 (1987): 124-138.

${ }^{81}$ Ávila, Tratado del amor de Dios, 10, OC I, 968.

${ }^{82}$ Ibid., n. 10, 969.

${ }^{83}$ Ibid., n. 11, 970.
} 
Vestir la librea de CRISto. Huellas de espiritualidad martirial en San Juan...

\section{El martirio en la predicación avilista}

No encontramos una predicación específica de Juan de Ávila sobre el martirio. Únicamente en dos sermones de santos ocupa un lugar, al final de su discurso: en el sermón de San Mateo, en el día de su fiesta, 21 de septiembre ${ }^{84}$, y en el de Santa Catalina, 25 de noviembre ${ }^{85}$, predicados en un monasterio de monjas (quizás el de Santa Clara de Montilla, aunque no se pueda asegurar). En ambos casos, la temática central no es el martirio, sino el llamamiento de Jesús a los pecadores y la conversión en el primero y la vigilancia en el segundo. Ambos terminan con una referencia al martirio que él adapta al auditorio, buscando la ejemplaridad para las monjas en el valor de la virginidad: San Mateo habría muerto predicando en Etiopía en defensa de la consagración virginal de Efigenia, amenazada por el rey Hircaco ${ }^{86}$; Santa Catalina, a quien describe como "doncella muy rica, muy sabia, muy hermosa y de gran linaje", fue consolada por Jesucristo en el momento de su martirio, cumpliéndose en ella la bienaventuranza de Mt 5,5; al golpe de la espada, salió de su cuerpo "un chorro de leche, para denotar que era limpia, que era castísima y que era toda blanca como paloma"; sepultada en el monte Sinaí, allí brotaría "un arroyo de olio" "87. Ambos fragmentos nos indican que Ávila no tuvo problema alguno en emplear este tipo de leyendas; habría que explorar sus fuentes entre las múltiples ediciones del Flos sanctorum renacentista (a partir de 1516), o la Leyenda de los santos (desde ca. 1490), en todo caso anteriores a las postridentinas (las Vitae Sanctorum de Lipomano y Surio son de 1575 y la de Alonso de Villegas de 1578$)^{88}$. No obstante, Ávila no pone el acento en lo extraordinario o milagroso, sino en el valor espiritual o moral que la leyenda puede transmitir a sus oyentes.

También resulta escasa la presencia de la doctrina tradicional sobre el martirio. En coherencia con la falta de centralidad del tema, no la encontramos expuesta como tal, sino traída en alguno de sus elementos para reforzar otra afirmación.

En las Lecciones sobre la primera canónica de San Juan, que se consideran predicadas en Zafra (1546 o 1549), el testimonio de los mártires era aducido para demostrar que se puede confiar en la palabra de Dios: los mártires creye-

\footnotetext{
${ }^{84}$ Sermón 77, OC III, 1037-1043.

${ }^{85}$ Sermón 80, OC III, 1073-1081.

${ }^{86}$ Sermón 77, 13-14, OC III, 1042-1043.

${ }^{87}$ Sermón 80, 18, OC III, 1081.

${ }^{88}$ José Araguiés Aldaz, "Los Flores Sanctorum medievales y renacentistas. Brevísimo panorama crítico", en Literatura medieval y renacentista en España: líneas y pautas, ed. Natalia Fernández Rodríguez y María Fernández Guerreiro (Salamanca: SEMYR, 2012), 349-361.
} 


\section{María Jesús Fernández Cordero}

ron las palabras concretas del Evangelio (Mt 10,32, o Mt 10,28) y por eso no temieron los tormentos y entregaron su vida. La intención aquí era convencer a los oyentes de que podían creer en el perdón de los pecados, prometido en 1 Jn 1,9, y seguía una valiosa reflexión sobre la Escritura como "traslado del corazón de Dios" $"$. En la lección siguiente, sobre la relación entre el conocimiento de Dios y la guarda de los mandamientos, un curioso diálogo con los oyentes venía a deshacer el argumento de quienes se disculpaban en no tener ocasión de ser mártires:

Hay personas que dicen: “ $¡ O h$, quién estuviese en tierra de moros, para morir allá por Cristo!" Perded ese deseo, que hágoos saber que vivís en tierra de moros y de turcos, donde podáis ser mártires. Imposible es que muera uno por la fe de Cristo y irse con todo eso al infierno ${ }^{90}$.

Y en un farragoso párrafo trataba de hacer comprender que quien moría mártir dejaba atrás todos los pecados, más allá de su arrepentimiento específico sobre ellos, porque "ya antepone a Cristo a todas las cosas". Citaba a Santo Tomás para afirmar que "no puede uno padecer martirio sin caridad"91. Frente a deseos de martirio ideales y devociones solo de palabra, el conocimiento de Dios debía ser "práctico", "vivo" y "que hace obrar"92.

Con este mismo carácter secundario aparece la doctrina del martirio en dos sermones del Santísimo Sacramento. En el Sermón 33, predicado en jueves santo, la casa en la que Jesús manda a sus discípulos preparar la pascua era vista como un símbolo de la Iglesia; en ella subrayaba con especial fuerza la novedad ${ }^{93}$ y exhortaba a morar en ella. Comparaba la imposibilidad de salvarse fuera de ella con la de no ahogarse para quienes, en el diluvio, no entraron en el arca. Aunque no lo indicaba, esta imagen procedía del De unitate Ecclesiae de San Cipriano ${ }^{94}$; pero inmediatamente citaba al obispo de Cartago para

\footnotetext{
${ }^{89}$ Ávila, Lecciones sobre la primera canónica de San Juan (I), lecc. 6a, OC II, 147.

${ }^{90}$ Ibid., lecc. $7^{\text {a }}$, OC II, 158.

${ }^{91}$ Id. Citaba la Summa theol., II-II, q. 124, a. 2 ad 2., en un latín no literal (seguramente de memoria), donde se dice que, en el martirio, la caridad es la virtud imperante y el motivo principal, y la fortaleza, la virtud de donde procede.

${ }^{92}$ Ibid., OC II, 159.

${ }^{93}$ Sermón 33, 9, OC III, 410: “¿Cuál es la casa donde tal novedad ha de hacer Cristo, que se acabe lo viejo y comience lo nuevo: nueva ley, nuevo sacerdocio, nuevo sacrificio, nuevo culto, y donde se había de cumplir lo escrito: Antiqua ne intueamini? (Is 43,18)".

${ }^{94}$ Cipriano, La unidad de la Iglesia, 6, en La unidad de la Iglesia. El Padrenuestro. A Donato, ed. Carmelo Failla (Madrid: Ciudad Nueva, 2001), 49. Cipriano utilizaba esta imagen a continuación de su más célebre frase: "No puede ya tener a Dios por padre quien no tiene a la Iglesia por madre. Si pudo salvarse alguien fuera del arca de Noé, también se salvará quien estuviera fuera de la Iglesia". Empleaba la ironía, pues Gén 7,21-22 afirma que "pereció toda carne (...), y toda la humanidad. Todo cuanto respira hálito vital, todo cuanto existe en tierra firme, murió".
} 
Vestir la librea de CRISto. Huellas de espiritualidad martirial en San Juan...

afirmar que ni siquiera el martirio es tal "fuera de la santa Iglesia romana"; castellanizaba así sus palabras:

Morir por Cristo fuera de la santa Iglesia romana no es martirio ni basta para salvarse; más es perfidia y porfía, que martirio cristiano; porque no acepta Dios honra que le hagan si deshonran a su esposa la Iglesia ${ }^{95}$.

El ejemplo sublime del martirio está aquí puesto al servicio del tema eclesiológico: la permanencia en la Iglesia, con una catequesis sobre las señales de la verdadera Iglesia (Escritura, sacramentos, primado pontificio).

Algo semejante ocurre en el Sermón 56. La intencionalidad principal de Ávila era convencer a los fieles de la necesidad de recibir con frecuencia la comunión. Ponía el ejemplo del "glorioso obispo y mártir San Cipriano", en la circunstancia de modificar la disciplina que alejaba de la comunión a los lapsos ante una persecución inminente, para que pudiesen mantenerse firmes en la confesión de la fe; insertaba una larga cita a este propósito:

(...) Porque a los que enseñamos y amonestamos que derramen su sangre por la confesión de la fe de Cristo, si les denegamos la sangre de Cristo, ¿cómo han de pelear? ¿O cómo les haremos idóneos para que beban la copa del martirio, si primero no les admitimos a beber en la Iglesia la copa del Señor, dándoles el derecho de la comunión?". Y un poco después dice: "No puede ser idóneo para recibir martirio a quien la Iglesia no arma para la guerra; y aquel ánima ha de desmayar y caer, la cual no recibe la santa Eucaristía para que la encienda y levante ${ }^{96}$.

Aunque insistirá en el efecto de la comunión de preservar del pecado mortal, se detenía un poco en el tema del martirio: pensando en la última persecución del fin de los tiempos, que no veía tan lejanos, creía que era necesario preparar a los cristianos para padecer por la fe; en todo caso, acercaba la posibilidad del martirio:

Y si, por pareceros que esta guerra no vendrá tan presto, no os queréis aparejar, a la puerta tenemos peligros de herejes y de los turcos, que no sabemos si será menester que ofrezcamos nuestras cabezas en confesión de la fe; y para estar fuertes en trance tan recio, dijo este santo bienaventurado que es cosa necesaria recibir el santo cuerpo y sangre de Jesucristo; y que aquel ánima ha de faltar y desmayar que no fuere esforzada por la sagrada comunión que recibe. Gran

\footnotetext{
${ }^{95}$ Ávila, Sermón 33, 9, OC III, 410. Es la doctrina de Cipriano, La unidad de la Iglesia, 14, ibid., 59 : "Inexplicable y grave es el pecado de la discordia, hasta el punto de que ni con el martirio se perdona. No puede ser mártir quien no está en la Iglesia".

${ }^{96}$ Sermón 56, 35, OC III, 761-762. Así como otras veces cita de memoria, este texto parece una traducción. Cf. Cipriano de Cartago, Cartas, ed. Ma Luisa García Sanchidrián (Madrid: Gredos, 1998), 241-243; es la carta de Cipriano y los obispos africanos a Cornelio, ante la inminente persecución de Galo.
} 


\section{María Jesús Fernández Cordero}

daño ha venido a la Iglesia por no entenderse, o no enseñarse, y no ponerse en obra aquesta verdad, que para confesión de la fe y para no caer en pecado mortal es remedio eficacísimo el recebir aqueste santo manjar. Y como dice este santo, no es justo que pidamos a los cristianos que estén firmes en la confesión de la fe, aunque sean atormentados, si no los armamos con la sagrada comunión ${ }^{97}$.

Aquí el martirio está, pues, al servicio del tema de la comunión, como ejemplo extremo de la necesidad y eficacia del sacramento. Pero nos permite observar que la predicación avilista quiso acercar la posibilidad del martirio alertando de dos de las fronteras que se iban dibujando -la herejía y el Turco- y, como Cipriano, quiso poner en acción una responsabilidad pastoral respecto a la fidelidad de los cristianos. Lo primero nos recuerda el empeño de Tomás Moro en plantear la pregunta por la disponibilidad al martirio ${ }^{98}$; lo segundo es coherente con la actitud que Ávila mantuvo siempre en los temas de reforma: aquello que la Iglesia pide, ha de sembrarlo, actuarlo y procurarlo primero; la continuidad con Cipriano en este sentido es reveladora de la asimilación o sintonía con el espíritu de los Padres ${ }^{99}$.

Un tratado menor, aún por explorar, es el Dialogus inter confessarium et paenitentem; pues bien, aquí encontramos, en boca del confesor, una instrucción sobre cómo meditar la pasión, con varios puntos; los últimos, tratan de que el cristiano integre en su vida la persecución y la disponibilidad al martirio:

Décimo, pensad el Cuerpo místico de Cristo, que son sus escogidos, cómo fueron todos crucificados, porque, desde Abel justo y Adán, todos los que piadosamente quieren vivir en Cristo nuestro Señor padecen trabajos y persecuciones; undécimo, desead ser mártir y imitar al Señor y a los suyos, y considerad, cuando los mártires estaban para padecer, de qué manera se aparejaban para el martirio, y pedid al Señor que os dé aquel mismo espíritu; duodécimo, imaginad que están los verdugos esperando que acabéis la oración para martirizaros, y de la manera que os aparejaríades para morir por Cristo. De esa manera salid de la oración, y así os ofreced al Padre encorporado con Cristo y con sus san-

\footnotetext{
${ }^{97}$ Sermón 56, 37, OC III, 762.

${ }_{98}$ Álvaro Silva, Tomás Moro. Un hombre para todas las horas (Madrid: Marcial Pons, 2007), analiza en el c. 5, "El martirio y el arte de vivir" (172-196), este interés que Moro plasmó en su Diálogo de la fortaleza contra la tribulación, como una pregunta para todo cristiano.

${ }^{99}$ Este aspecto ha sido subrayado recientemente por Ricardo Aldana Valenzuela, "La reforma de la Iglesia en la escucha de la palabra de Dios. Una mirada al magisterio de San Juan de Ávila", Studia Cordubensia 6 (2013): 8. Gaspar Hernández Peludo, "Los Padres de la Iglesia en la vida del sacerdote según San Juan de Ávila”, en Actas del Congreso Internacional. El presbítero secular del siglo XXI a la luz del magisterio de San Juan de Ávila, coord. Francisco Juan Martínez Rojas (Jaén: Obispado de Jaén, 2020), 199-228.
} 
Vestir la librea de CRIsto. Huellas de espiritualidad martirial en San Juan...

tos, y ofreced aquella pasión por vuestros pecados y por los del mundo, y rogad por todos los amigos y enemigos vuestros, etc. ${ }^{100}$

La posibilidad del martirio, que en la predicación se acercaba aludiendo a los fenómenos de la herejía y el peligro turco, se convertía, en los consejos del confesor y acompañante espiritual, en el cultivo de las disposiciones propias de la entrega martirial: aquellas que cada uno ha de descubrir para sí contemplando la pasión, la vida de la Iglesia en sus santos y el final de los mártires. Puesto que hacía de esto el modo de salir de la oración, se ha de entender que esta dimensión martirial constituía un cauce importante para vincular la oración y la vida: portaba en sí la imitatio Christi y la ofrenda sacerdotal. No es extraño, pues, que algo de esto encontremos en el modo en que Ávila acompañaba a las personas.

\section{El "martirio de amor" o la dimensión martirial del cristianismo}

Juan de Ávila es también heredero de la larga tradición de la Iglesia que identificaba el martirio incruento. Orígenes difundió la expresión "martirio de la conciencia"101 y San Atanasio entendió la ascesis como "martirio interior" para el perfecto seguimiento de Cristo ${ }^{102}$. Clemente de Alejandría afirmó que "cualquier alma que se comporte de manera limpia reconociendo a Dios y sea obediente a los mandamientos, es mártir con vida y palabra, sea cual fuere su salida del cuerpo, pues vierte su fe, igual que la sangre, durante toda la vida hasta el final"; lo llamó "martirio gnóstico", por el reconocimiento del Señor, el amor a Él y la intelección de su evangelio ${ }^{103}$; "cuantos ponen en práctica los mandamientos del Señor, son mártires en cualquier circunstancia" y dan testimonio de É $1^{104}$. San Agustín habló de las tentaciones como "persecuciones del diablo" y, por tanto, superarlas equivale a ser coronado como "mártir" 105 ; hacía un paralelismo entre las coacciones a los mártires para sacrificar a los ídolos y las tentaciones que sufría el enfermo para aplicar remedios mágicos;

\footnotetext{
100 Ávila, Dialogus inter confessarium et paenitentium, 19, OC II, 782-783.

${ }^{101}$ Jean Kirchmeyer, “(Église) GrecquE”, en DSp., t. 6, col. 861.

${ }^{102}$ Atanasio, Vida de Antonio, 47, ed. Paloma Rupérez Granados (Madrid: Ciudad Nueva, 1995), 82: "vivía día tras día un martirio interior, combatiendo las batallas de la fe, y practicaba la ascesis con una intensidad cada vez mayor".

${ }^{103}$ Clemente de Alejandría, Stromata, IV, c. 4, 15, ed. Marcelo Merino Rodríguez (Madrid: Ciudad Nueva, 2003), 79.

${ }^{104}$ Ibid., c. 7,43, 119.

${ }^{105}$ San Agustín, Sermón IV, 37, en Obras, t. VII: Sermones $\left(1^{\circ}\right)$, edición bilingüe (Madrid: BAC, 1986), 86.
} 


\section{María Jesús Fernández Cordero}

ante estas propuestas que desafiaban la fe cristiana, exhortaba: "tienes que enfrentarte a una lucha igual; espera una palma igual"; el combate del martirio no era exclusivo del estadio; por eso advertía a los cristianos: "no es necesario desear una persecución como la que ellos padecieron, pues a diario nos hallamos con la tentación que es la vida humana"106. La ascesis, la mortificación, la penitencia, la castidad, la obediencia a la voluntad del Señor, aparecen asociadas al martirio en esta herencia cultural que Ávila recibió. Pero él utilizó su propio lenguaje, de tipo experiencial o espiritual, a la hora de referirse al martirio incruento.

"Martirio de amor" es el que padeció la Virgen María entre la ascensión de su Hijo a los cielos y su propia asunción. Este martirio aparece caracterizado por el sentido general de la vida como un "destierro" y por la vivencia de la "ausencia" de Jesús en el modo único en que su Madre podía experimentarla; su "grandísimo amor", que la hacía bienaventurada, era también su "gran sayón", que la atormentaba por la dilación en su deseo de ver a Dios, proporcional al amor 107. Los "amigos de Dios" que estuvieron presentes en la muerte de Jesús sufrieron un "martirio de compasión interior", también provocado por "el interior amor"; pero María, que fue la que más padeció allí, hubo de beber "el cáliz de amargura de la ausencia" del Hijo ${ }^{108}$. Ávila enfocó este tiempo de la vida de María desde una perspectiva mística: se trata de un amor que hiere y ata; estas cualidades, que afectan a ella y a Dios -"Herida y presa estaba la Virgen del amor divinal, más que ninguna criatura; y herido y preso tenía a su Señor y su Dios, más que ninguna criatura" ${ }^{109}-$, son las que hacen que ella padezca un martirio de amor. Ávila continúa así la tradición que, desde San Bernardo, habla del martirio de la Virgen (martyr in anima ${ }^{110}$ por su unión a la pasión de Cristo, compassio Mariae). Más aún, predica que fue martirio toda la vida de María, antes y después de la Pasión ${ }^{111}$. Su ejemplo habría ayudado a los cristianos de entonces a desear como ella ver a Dios en el cielo, en una época de persecuciones en que estaban "esperando cada día el martirio"

Sin embargo, es en el Epistolario donde mejor podemos captar la existencia de una espiritualidad martirial, inculcada por el Maestro al acompañar

\footnotetext{
${ }^{106}$ San Agustín, Sermón 318, 3, en Obras, t. XXV: Sermones (5º), edición bilingüe (Madrid: BAC, 1984), 622-623.

107 Ávila, Sermón 70, 8-9, OC III, 949.

${ }^{108}$ Ibid., 10, 950.

${ }^{109}$ Ibid., 21, 954.

${ }^{110}$ San Bernardo, "Dominica infra octava Asumptionis. Domingo dentro de la octava de la Asunción”, 5, en Obras completas, t. IV: Sermones litúrgicos (2), ed. bilingüe (Madrid: BAC, 1986), 414-415.

111 Ávila, Sermón 70, 27, OC III, 956.

${ }^{112}$ Ibid., n. 49, 965.
} 
Vestir la librea de CRISto. Huellas de espiritualidad martirial en San Juan...

situaciones de tribulación, adversidad o persecución. Sin ser exhaustivos, sí podemos reseñar aquí algunos aspectos destacados.

\subsection{La librea de Cristo en el martirio de amor}

La Carta 23, dedicada a una señora enferma, resulta especialmente significativa, pues en ella encontramos de nuevo la imagen de la librea:

Sola la quiere Dios y atribulada, no por malquerencia, sino después que su Hijo bendito fue atribulado, no quiere ver a sus hijos vestidos de otra librea. Esto es lo que delante sus ojos parece hermoso, ver en nosotros la imagen de su unigénito Hijo ${ }^{113}$.

En esta ocasión, Ávila está proponiendo la imagen de la librea a una mujer, aunque lo hace desde la general filiación cristiana. Ciertamente, hay noticias del uso de vestiduras heráldicas por parte de las mujeres medievales, portando las armas del esposo, del padre o, más excepcionalmente, escudos partidos con las armas de ambos significando la unión de linajes ${ }^{114}$; y también noticias de la donación de libreas incluso de color carmesí a mujeres vinculadas a la corte $^{115}$. En el texto que nos ocupa, el simbolismo de la librea se mantiene intacto y es claramente martirial: "la empresa del amor no es palabras, sino dolor, crueles tormentos, deshonras del mundo, desamparo de criaturas y ausencia del consuelo del Criador", cosas todas que hay que pasar "a semejanza de mártir". Esta capacidad de soportar el sufrimiento se apoyaba en la esperanza de ver a Dios tras la muerte, en analogía con la entrada directa del mártir en el cielo. El carácter espiritual de este martirio era expresado así:

Trabajemos nosotros de ser mártires en la paciencia, que aunque no es tan grande nuestro trabajo como el de ellos [los mártires], es más largo. Y debemos de desear que esta vida no nos sea apacible, mas un puro martirio; ésta fue la vida de nuestro Señor y ésta quiere que sea la nuestra. Muchos fueron mártires de fe, mas al fin muchos han ido al cielo sin serlo; mas mártires de amor todos lo hemos de ser, si queremos ir allá. Éste nos ha de atormentar, haciéndonos tomar pena porque ofendimos a Dios y porque otros le ofenden; éste nos ha de quitar todos los consuelos de acá y ponernos la cruz encima de los hombros; éste nos ha de hacer abrazar los trabajos y pasar por encima de ellos con la llama del amor; que encendido, éste hace sufrir deshonras

\footnotetext{
${ }^{113}$ Carta 23, OC IV, 146.

${ }^{114}$ Laurent Hablot, "Revêtir l'armoirie. Les vêtements héraldiques au Moyen Âge, mythes et réalités", Espacio, tiempo y forma. Serie VII: Historia del Arte 6 (2018): 73-74.

${ }^{115}$ Germán Gamero Igea, "Las libreas en el séquito de Fernando el Católico...”, 171-172: los oficiales mayores y sus mujeres recibieron vestiduras o sedas carmesíes para la celebración de las bodas del príncipe Juan en Burgos (1497).
} 


\section{María Jesús Fernández Cordero}

sin las sentir, y sacar a uno de sí, como el vino al borracho. Que en esto se parece el amor, que el que lo tiene no busca a sí mismo, sino a solo Dios y su voluntad ${ }^{116}$.

El modo en que Ávila se explica apunta, no a una especie de masoquismo espiritual, sino a una participación del cristiano en el misterio de la redención. Por eso, la mirada y el corazón han de estar puestos en el Crucificado, apareciendo de nuevo la redamatio: "Cristo padeció por nuestro amor, padezcamos por el suyo". Se trata de aceptar y asumir lo mismo que él (...), hasta el extremo: "por mí murió, sea mi vida por su amor una muerte continua" 117.

Por tanto, la librea mantiene todo su simbolismo de pertenencia e identificación con Cristo. Esto se corrobora en otras cartas dirigidas a mujeres. En la Carta 29, a una señora ilustrísima, la imagen aparece en relación con la filiación divina, significa ser amada y tratada por Dios como hija: "Téngase por indigna de ser ella vestida de la librea que el Hijo de Dios y su santa Madre fueron vestidos" 118 . En la Carta 79, en la que trata de fortalecer a una doncella en la perseverancia advirtiéndole de los diversos modos en que podía ser apartada del seguimiento de Cristo, la exhorta a abrazar las penas que conlleva; tras recordarle la Pasión, le señala la mística esponsal:

Por tanto, esforcémonos en el Señor y armémonos con las armas de su pasión y penas, que en ellas hallará nuestra ánima tanta fortaleza, que en ninguna cosa la pueda vencer. Y tome la esposa a su Cristo como manojo de mirra y traiga la amargura de Él en el corazón (cf. Vg. Cant 1,12), para que, pensando en las penas de Él, se consuele en las proprias y lo tenga por mercedes, como lo son; y ámelas tanto que se halle con ellas favorida y llena de joyas, y tiemble de verse sin ellas. Y siéntase como desnuda cuando no está vestida de la librea de su Esposo, que es angustias y trabajos. Y ansí huirá el demonio, que nos quería hacer dejar el camino de Dios, contándonos que pasábamos mucho, viéndonos amar los trabajos por amor de Aquel que por nos los pasón ${ }^{119}$.

A la imagen de la librea, precedida por la de las armas (combate y heráldica) de la Pasión, se une otra temática tradicional: la del fasciculus myrrhae, difundida por la espiritualidad cisterciense desde San Bernardo al comentar el versículo del Cantar: Fasciculus myrrhae dilectus meus mihi: inter uvera mea commorabitur (bolsita de mirra es mi amado para mí, que reposa entre mis pechos); el abad de Claraval exhortaba al monje:

\footnotetext{
116 Ávila, Carta 23, OC IV, 147-148.

${ }^{117}$ Ibid., 148.

${ }^{118}$ Carta 29, OC IV, 176.

${ }^{119}$ Carta 79, OC IV, 334-335.
} 
no consentirás que te arranquen jamás de tu pecho esa querida bolsita de mirra, reteniendo siempre en tu memoria y acariciando en su asidua meditación todos los dolores que por ti padeción ${ }^{120}$,

hasta poder hacer propias estas palabras de la esposa. Para Ávila, la doncella a la que se dirige -probablemente una mujer que ha escogido la vida de beata- ha de fortalecerse contemplando la Pasión y correspondiendo en amor de tal modo que ella misma quede revestida de Cristo (librea) y hermoseada con virtudes (joyas), por la acogida en su corazón de lo que su Esposo pasó por ella (manojo de mirra).

En todas estas orientaciones espirituales, no hay que olvidar ni la centralidad del amor ni la alegría. De hecho, en una carta a Juan de Lequetio ${ }^{121}$, Ávila se refiere a todo esto como la "doctrina del gozo en la cruz". Parece resonar de nuevo el consejo de San Bernardo a los monjes para llevar el fasciculus myrrhae "no atrás, sobre los hombros, sino ante nuestros ojos, no sea que soportéis el dolor sin su perfume, pues os abrumaría su peso y no os aliviaría su fragancia" ${ }^{122}$; Ávila, desde la idea de la imiatatio Christi, recomendaba a su discípulo no perder de vista el motivo fundamental ni el consuelo que encerraba:

El Señor llevó su cruz, poniendo delante el gozo (cf. Vg. Heb 12,2) que de nuestro bien Él había de sacar mediante su pasión; y nosotros debemos llevar la nuestra, poniendo delante el contentamiento de su voluntad y la hermosura de la librea de estar vestido al traje de É $1^{123}$.

Todavía en otra carta insiste en que hay que reconocer en esto el amor de Dios: “¿Por qué no le daré gracias, pues que me viste la librea de su amado Hijo? ¿Por qué no terné esperanza que me hará partícipe de su gloria, pues me veo serlo en sus trabajos?"124.

\subsection{Espiritualidad martirial en la misión}

El espíritu martirial se hace presente en todas las situaciones de persecución y en aquellas que exigen del cristiano un testimonio consistente en la disponibilidad a renunciar y perder todo por Cristo. En la Carta 2, escrita quizás para el dominico Fr. Alonso de Vergara con motivo de una persecución, encontramos una retórica que espolea al destinatario para que asuma

\footnotetext{
${ }^{120}$ San Bernardo, "Sermón 43", II.2, en Obras completas, t. V: Sermones sobre el Cantar de los Cantares., ed. bilingüe (Madrid: BAC, 1987), 583.

${ }^{121}$ Sobre este discípulo, Fernández Cordero, Juan de Ávila, 315-317.

${ }^{122}$ San Bernardo, "Sermón 43", III.5, en Obras completas, t. V, 585.

${ }^{123}$ Ávila, Carta 203, OC IV, 666.

${ }^{124}$ Carta 81, OC IV, 342.
} 


\section{María Jesús Fernández Cordero}

con madurez las consecuencias del seguimiento de Cristo. La persecución por parte de "los mundanos" tiene que ver con el hecho de que él "ha muerto" a lo que ellos adoran ${ }^{125} \mathrm{y}$ ha predicado una doctrina que es de Dios; por tanto, este morir a lo mundano ha de ser real: "No estime a Dios en tan poco, que quiera dar poco por Él"126. Aquí entra de lleno el tema de la honra:

¿Qué mayor honra, padre mío, que padecer por Cristo! (...) ¿Qué se queja, padre, de palabras y estimas de hombres y juicios de ciegos? (...) Pues, si Él lo abona, ¿qué va en que todo lo demás lo condene? (...) Aún no ha vuestra reverencia peleado hasta derramar la sangre (cf. Heb 12,4); aún no es compañero y semejante en los trabajos al Apóstol, que decía: Cada día me veo a punto de muerte (1 Cor 15,31$)^{127}$.

De nuevo, Pablo es el gran referente de los trabajos y sufrimientos apostólicos, sostenido por la fe (2 Tim 1,12); su modelo indica el camino de la entrega: "Ofrezca, padre, su vida y honra en las manos del Crucificado, y hágale donación de ella, que Él la porná en cobro" 128 .

Esta actitud significaba para Ávila una disposición interna no solo general, sino aplicada a la situación concreta. Era el modo de fidelidad al Señor que capacitaba a la persona para adquirir una libertad evangélica frente a las presiones y los intereses mundanos. De ahí que fuera importante también para impulsar la reforma de la Iglesia. Podemos verlo con claridad en la carta que escribe al obispo de Córdoba, Cristóbal de Rojas y Sandoval, con motivo de la celebración del concilio provincial de Toledo de 1565 , cuya presidencia le correspondió a causa de la prisión del arzobispo Bartolomé Carranza ${ }^{129}$. El núcleo espiritual de la carta consiste en enfocar la misión del obispo desde la teología del envío y en proponer una actitud interior y una actuación exterior conformes con él: "la embajada de parte de Dios" que recibe el ministro se ha de realizar a semejanza de la del Hijo "cuando el Padre le envió por embajador al mundo". Esta conformidad exige "ir mortificado" hasta en los afectos que son "tan amados como a su sangre"; la simbología de la sangre alude tanto a los vínculos de parentesco como a la vida que se puede perder; por tanto, estamos ante un lenguaje martirial:

Aquel saca sangre que ofrece a Dios lo que mucho le duele, y ésta es digna recompensa del cristiano para con nuestro Señor, que pues Él derramó la sangre por nosotros y pues Él murió por nosotros, nosotros muramos por Él, o perdiendo

\footnotetext{
${ }^{125}$ Carta 2, OC IV, 16.

${ }^{126}$ Ibid., 18.

${ }^{127}$ Ibid., 19.

${ }^{128}$ Ibid., 20.

${ }^{129}$ Fernández Cordero, Juan de Ávila..., 337-346.
} 
Vestir la librea de CRISto. Huellas de espiritualidad martirial en San Juan...

la vida corporal o perdiendo los afectos, por muy entrañables que nos sean, porque, a trueco de haber el Señor dado su vida y su sangre, dar nosotros, no lo que nos duele, sino una cosa de poco valor, es caer en aquella maldición: Maledictus dolosus qui habet in grege suo masculum, et offert Domino debile (Mal 1,14) ${ }^{130}$.

La sangre como símbolo de los afectos entrañables que se han de sacrificar al Señor nos habla de un martirio interior y espiritual que implica actos espirituales concretos que ponen en riesgo bienes concretos; es mortificación, ascesis y sacrificio, pero es también riesgo, valentía, libertad y entrega. Es una "muerte" fecunda:

Alce los ojos vuestra señoría al Hijo de Dios puesto en una cruz, desnudo y crucificado, y procure desnudarse del mundo y de la carne, y sangre, codicia, y de honra, y de sí mismo, para que así sea todo él semejante a Jesucristo y sea su embajada eficaz y fructuosa. Muera a todo y vivirá a Dios, y será causa para que otros vivan, porque, si esto no lo hace, perderse ha a sí y a los otros, pues la palabra de Cristo Señor nuestro no puede faltar: Nisi granum frumenti (Jn 12,24).

¡Oh muerte dichosa, pues tantas vidas y tan preciosas y eternas se siguen de ella, y desdichado de aquel que, por quererse quedar encima de la tierra, pretendiendo algo de ella, se pierde a sí y a los que pudiera ganar! $!^{131}$

\subsection{El martirio interior en la vida espiritual}

Ávila invocó varias veces la autoridad del obispo de Hipona para referirse al carácter martirial de la lucha contra el pecado y de la obediencia a la voluntad de Dios. Decía a una monja:

La vida del cristiano dice San Agustín que toda es martirio, y ansí es verdad que, si miráis qué se pasa por no pecar y por hacer la voluntad del Señor en cualquier cosa que acaeciere, veis que los que mueren por la fe de nuestro Señor y los que viven por no perder su obediencia y amor, todos son mártires. Muchos sayones y fuegos y otros tormentos, combatían la fe del mártir para se la quitar; mas muchos más combaten la castidad, la caridad, la paciencia, la obediencia de Dios, para nos la quitar ${ }^{132}$.

Esta idea del martirio por no pecar y por hacer la voluntad de Dios le permitía introducir este sentido martirial en la vida espiritual como comba-

\footnotetext{
${ }^{130}$ Ávila, Carta 182, OC IV, 602-603. La cita de Malaquías: "Maldito el que tiene un macho en su rebaño y sacrifica un animal defectuoso".

${ }^{131}$ Ibid., 603-604.

${ }^{132}$ Carta 66, OC IV, 294. San Agustín había dicho: "Los mártires murieron para no pecar" (Sermón 318, 2, en Obras, t. XXV, 622).
} 


\section{María Jesús Fernández Cordero}

te: "guerra de amor", con toda clase de tribulaciones y tentaciones, de fuera (tormentos infligidos por "sayones hombre") y de dentro (por "sayones diablos") $)^{133}$.

Cuando los que martirizan son los hombres, consuela Dios; pero el mayor sufrimiento se produce en los martirios interiores y secretos en los que "el que desconsuela es nuestro Señor, que se esconde, y los demonios, como crueles sayones, por mil artes atormentan al ánima”. Es el martirio más íntimo y difícil de soportar:

Y está el hombre entero todo, de dentro y fuera, puesto en desconsuelo de cruz; gime y pide socorro a nuestro Señor; y no sólo se hace sordo y escondido más que detrás de siete paredes, mas aun siente que el Señor se desvía de ella, no sólo no dándole favor, mas aun enseñándole el disfavor, como lo hizo con la Cananea, que primero no la respondió y después la llamó de perra (cf. Mt 15,26). Hora es aquella de grande angustia, y en ninguna parte halla el ánima reposo, como cuando uno se ahoga en un profundo mar, sin hallar en qué hacer pie, o como el que está atado de pies y manos, y prueba a levantarse, y no puede. Porque así como aquel a quien Dios consuela, ningún tormento ni pena le puede desconsolar, así al que Dios desconsuela ninguna cosa le puede alegrar. (...) Este martirio ha de pasar por su Esposo el ánima que por Él desea traer empresa de amor $^{134}$.

Para este martirio pone como referencia la tristeza hasta la muerte y el sudor de sangre de Jesús en la noche de Getsemaní, y la mencionada disposición de San Pablo a morir. Entonces la gran tentación es la desconfianza, porque "no creyendo ser amado, enflaquece en el amor". Toda la orientación de Ávila en estas tribulaciones interiores consiste en alimentar la fe en el amor de Dios:

Y de estos males libra la fe, junta con obediencia, haciéndonos creer que Dios nos ama, y entonces más cuando más se esconde su amor y cuando más riguroso y cruel se nos muestra. Porque la condición de la verdadera fe es creer no sólo con prendas y señales, mas sin ella; y no solo sin ellas, mas contra ellas, pareciendo en esto a cualquier virtud, que allí demuestra su mayor fuerza y resplandor donde menos ayudas y mayores impedimentos se ofrecen.

Esta fe que se mantiene en estas circunstancias -cuando Dios se escondees la que llega a ver "lo invisible" y escondido; la que cree en el amor y el favor de Dios cuando la razón o los sentidos le hablan de disfavor. Así,

por mitad de las lanzas -que son los disfavores de Dios que sentimos- entramos, y llegamos hasta lo más secreto del corazón de Dios, y conocemos que nos

\footnotetext{
${ }^{133}$ Ávila utilizaba estas expresiones al dirigirse a una mujer y le ponía como ejemplo a las mártires atormentadas en su cuerpo. Carta 19, en OC IV, 119.

${ }^{134}$ Carta 175. A una religiosa, hija suya espiritual, en OC IV, 578-579.
} 
Vestir la librea de CRISto. Huellas de espiritualidad martirial en San Juan...

ama, aunque muestre señales de desamor, las cuales entonces estimamos según verdad cuando las tomamos por prueba de nuestra fe, y ejercicio de nuestro amor, y acrecentamiento de nuestra corona, y materia de nuestra obediencia ${ }^{135}$.

El modo en que Ávila sostiene este tipo de martirio se fundamenta en la absoluta confianza en el amor de Dios. Recomienda con Sab 1,1: "sentid de Dios en bondad" "136, afianzando el sentido de la gracia y la misericordia de Dios.

\section{Conclusión}

El recorrido que hemos realizado fundamenta la afirmación de una espiritualidad martirial en San Juan de Ávila. Muy probablemente enraizada en la experiencia de la cárcel, se desplegó en su predicación y, sobre todo, en sus cartas de acompañamiento espiritual, en las que late su propia interioridad, a veces de modo muy directo, como en las oraciones que inserta en ellas, y a veces a través de consejos que traslucen la sabiduría de quien puede guiar en el camino. En todo lo dicho están los elementos esenciales de una teología del martirio -la llamada a reproducir la imagen de Cristo, la filiación divina, la obediencia a la voluntad de Dios, la actuación de las virtudes cardinalestransmitida en el cauce de una espiritualidad vivida.

La imagen de la librea, de resonancias medievales, expresa el núcleo de esta teología y espiritualidad: la imitiatio Christi $^{137}$, que busca compartir o participar de los sufrimientos de Cristo (el Señor y el Esposo), en retorno de amor (redamatio). Al confesar la pertenencia al Señor y la configuración con Él, vestir su librea se convierte en testimonio de Él y en la mayor merced y honra que puede recibir su servidor. Este núcleo está en sintonía y continuidad con la experiencia de los mártires en el cristianismo primitivo ${ }^{138}$. La ofrenda del martirio (exterior e interior) nos permite situarla como dimensión de la espiritualidad sacerdotal que caracteriza al Maestro Ávila; forma parte de la llamada a todos los cristianos, varones y mujeres, en el sacerdocio bautismal y en el ministerial, y compromete la misión. La esperanza de entrar en el cielo, de alcanzar la corona de los mártires, sostiene todo martirio, pues es la esperanza de participar en la victoria de Cristo.

\footnotetext{
${ }^{135}$ Ibid., 579.

${ }^{136}$ Ibid., 581. Traduce la Vulgata: "Sentite de Domino in bonitate”. La Biblia de Jerusalén traduce: "pensad rectamente del Señor".

${ }^{137}$ Gabino Uríbarri, "Fundamentos teológicos del martirio cristiano", en La confesión de la fe, ed. María Encarnación González Rodríguez (Madrid: EDICE, 2013), 37-84.

${ }^{138}$ Valero, "Martirio y libertad...", 137: "Se sienten imitadores de Cristo, y esta imitación la viven como una gracia de participación en el misterio salvador del Señor".
} 


\section{María Jesús Fernández Cordero}

El martirio, en una u otra modalidad, forma parte del discipulado y seguimiento de Cristo: "nos dejó esta enseñanza, que si queríamos ir donde está Él, que fuésemos por el camino por donde fue Él" ${ }^{139}$. Supone comunidad de destino con el Señor:

Mas, pues su bendita boca llama bienaventurados a los que lloran, a los que padecen hambre y sed, a los que padecen persecuciones (cf. Mt 5,5-6.10) y toda su vida no fue sino un continuo martirio, ¿qué duda nos queda a los que somos discípulos suyos, sino que firmemente creamos que este es el camino de la salud? No dudéis, hermanas muy amadas, de seguir la luz, que es Cristo; que, sin falta, si vais por donde Él fue, iréis a donde Él fue; porque palabra suya tenemos que adonde Él estuviere, estará su sirviente (cf. Jn 12,26) ${ }^{140}$.

\section{Bibliografía}

Abad, Camilo Ma " "El proceso de la Inquisición contra el beato Juan de Ávila. Estudio crítico a la luz de documentos desconocidos". Miscelánea Comillas 6 (1946): 95-168.

Agustín, San. Obras, t. VII: Sermones ( $\left.1^{\circ}\right)$, edición bilingüe. Madrid: BAC, 1986. Agustín, San. Obras, t. XXV: Sermones (5), edición bilingüe. Madrid: BAC, 1984. Aldana Valenzuela, Ricardo. "La reforma de la Iglesia en la escucha de la palabra de Dios. Una mirada al magisterio de San Juan de Ávila". Studia Cordubensia 6 (2013): 5-144.

Aranda, Gabriel. Vida del siervo de Dios exemplar de sacerdotes el Venerable Padre Fernando de Contreras, natural de esa ciudad de Sevilla, del hábito clerical de N. P. S. Pedro. Sevilla: Tomás López de Haro, 1692.

Aragüés Aldaz, José. "Los Flores Sanctorum medievales y renacentistas. Brevísimo panorama crítico", en Literatura medieval y renacentista en España: líneas y pautas, editado por Natalia Fernández Rodríguez y María Fernández Guerreiro, 349-361. Salamanca: SEMYR, 2012.

Atanasio. Vida de Antonio, editado por Paloma Rupérez Granados. Madrid: Ciudad Nueva, 1995.

Ávila, San Juan de. Obras completas. Madrid: BAC, 2000-2003, 4 vols.

Barrios Aguilera, Manuel. "La nueva frontera. El reino de Granada ante el mundo islámico en el siglo XVI". En Actas del Congreso la Frontera Oriental Nazarí como sujeto histórico (s. XIII-XVI): Lorca-Vera, 22 a 24 de noviembre de 1994, coordinado por Pedro Segura Artero, 583-610. Almería: Instituto de Estudios Almerienses, 1994.

\footnotetext{
139 Ávila, Carta 58, OC IV, 269.

${ }^{140}$ Carta 56, OC IV, 263.
} 
Vestir la librea de CRIsto. Huellas de espiritualidad martirial en San Juan...

Barrios Aguilera, Manuel y Sánchez Ramos, Valeriano. Martirios y mentalidad martirial en las Alpujarras (De la rebelión morisca a las Actas de Ugijar). Granada: Universidad de Granada, 2001.

Bataillon, Marcel. "Jean d'Avila retrouvé (A propos des publications récentes de D. Luis Sala Balust)". Bulletin Hispanique 57/1-2 (1955) 5-44.

Beltrán, José Luis. "«Aun a costa de la propia vida». Martirio y misión en el mundo ibérico de la Edad Moderna", en Identidades y fronteras culturales en el mundo ibérico en la Edad Moderna, editado por José Luis Bertrán, Bernat Hernández y Doris Moreno, 283-295. Barcelona: Universitat Autònoma de Barcelona, 2016.

Bernardo, San. Obras completas, t. IV y V. Madrid: BAC, 1986-1987.

Bohigues Fernández, Santiago. "San Juan de Ávila y su vocación martirial". Burgense 56/1 (2015): 255-272.

Cañeque, Alejandro. Un imperio de mártires. Religión y poder en las fronteras de la Monarquía Hispánica. Madrid: Marcial Pons, 2020.

Cipriano. La unidad de la Iglesia. El Padrenuestro. A Donato, editado por Carmelo Failla. Madrid: Ciudad Nueva, 2001.

Cipriano de Cartago. Cartas. Editado por $\mathrm{M}^{\mathrm{a}}$ Luisa García Sanchidrián. Madrid: Gredos, 1998.

Díaz Lorite, F. Javier. Experiencia del amor de Dios y plenitud del hombre en San Juan de Ávila. Madrid: 2007.

Esquerda Bifet, Juan. Diccionario de San Juan de Ávila. Burgos: Monte Carmelo 1999.

Brigit G. Ferguson. "The Pleasure of Martyrdom”. Mirabilia 18 (2014): 116-136.

Fernández Álvarez, Manuel. Tres embajadores de Felipe II en Inglaterra. Madrid: CSIC, 1951.

Fernández Conti, Santiago. "Suárez de Figueroa, Gómez (I duque de Feria)". En Felipe II (1527-1598). La Configuración de la Monarquía Hispánica, dirigido por José Martínez Millán y Carlos J. de Carlos Morales, 484-485. Salamanca: Junta de Castilla y León, 1998.

Fernández Cordero, María Jesús. Juan de Ávila (1499?-1569). Tiempo, vida y espiritualidad. Madrid: BAC, 2017.

Fernández Cordero, María Jesús. “«Dar el corazón a Dios». La redamatio en San Juan de Ávila", en San Juan de Ávila, Doctor de la Iglesia. Actas del Congreso Internacional, editado por Juan Aranda Doncel y Antonio Llamas Vela, 427-461. Córdoba: Diputación de Córdoba, 2013.

Gamero Igea, Germán. "Las libreas en el séquito de Fernando el Católico: relaciones y representaciones de los poderes cortesanos". Studia histórica. Historia Medieval 36/1 (2018): 161-194. 


\section{María Jesús Fernández Cordero}

Granada, Fray Luis de y Muñoz, Licenciado Luis. Vidas del Padre Maestro Juan de Ávila, editado por Luis Sala Balust. Barcelona: Juan Flors, 1964.

Greenfield, Amy Butler. Un rojo perfecto. Imperio, espionaje y búsqueda del color del deseo. Valencia: Universitat de València, 2010.

Hablot, Laurent. "Le double du prince. Les livrées emblématisées à la cour, un outil politique reflet d'une nouvelle conception du pouvoir". En La cour du prince, editado por Jacques Paviot et al., 281-299. Paris: Honoré Champion, 2011.

Hablot, Laurent. "Revêtir l'armoirie. Les vêtements héraldiques au Moyen Âge, mythes et réalités". Espacio, tiempo y forma. Serie VII: Historia del Arte 6 (2018): 55-88.

Hernández Peludo, Gaspar. "Los Padres de la Iglesia en la vida del sacerdote según San Juan de Ávila”. En Actas del Congreso Internacional. El presbítero secular del siglo XXI a la luz del magisterio de San Juan de Ávila, coordinado por Francisco Juan Martínez Rojas, 199-228. Jaén: Obispado de Jaén, 2020.

Jiménez Pablo, Esther. "El martirio en las misiones durante el siglo XVII: devoción y propaganda política". Chronica nova 43 (2017): 139-165.

Mâle, Emile. El arte religioso de la Contrarreforma. Estudios sobre la iconografía del final del siglo XVI y de los siglos XVII y XVIII. Madrid: Encuentro, 2001.

Martínez Millán, José. "Cambios en la espiritualidad de Juan de Ávila". En Juan de Ávila, unicus et multiplex. Una visión multidisciplinar, editado por $M^{a}$ Dolores Rincón González, Ignacio Pulido Serrano y Natalia Soria Ruiz, 131-157. Madrid: FUE-Universidad Pontificia de Salamanca, 2021.

Osuna, Fray Francisco de. Ley de amor santo. En Místicos franciscanos españoles t. I, editado por Fr. Juan Bautista Gomis, 221-700. Madrid: BAC, 1948.

Pastore, Stefania. Una herejía española. Conversos, alumbrados e Inquisición (1449-1559). Madrid: Marcial Pons, 2010.

Pastoureau, Michel. "Le temps mis en couleurs: des couleurs liturgiques aux modes vestimentaires (XIIe-XIIIe siècles). Bibliothèque de l'École des chartes, 157/1 (1999): 111-135.

Proceso de beatificación del Maestro Juan de Ávila, editado por José Luis Martínez Gil. Madrid: BAC, 2004.

Pulido Serrano, Juan Ignacio. "Experiencia vital y elaboración de una fórmula conciliadora en la obra de Juan de Ávila". En El Maestro Juan de Ávila (1500?-1569). Un exponente del humanismo reformista, editado por Ma Dolores Rincón González y Raúl Manchón Gómez, 171-193. Madrid: FUE - Universidad Pontificia de Salamanca, 2014. 
Vestir la librea de CRISto. Huellas de espiritualidad martirial en San Juan...

Pulido Serrano, Juan Ignacio. "Juan de Ávila y el problema morisco". En Juan de Ávila, unicus et multiplex. Una visión multidisciplinar, editado por $\mathrm{M}^{\mathrm{a}}$ Dolores Rincón González, Ignacio Pulido Serrano y Natalia Soria Ruiz, 707-731. Madrid: FUE- Universidad Pontificia de Salamanca -, 2021.

Rordorf, Willy. "Theólogie et spiritualité du martyre", en "Martyre", Dictionnaire de spiritualité, ascétique et mistique, t. X, cols. 726-732. Paris: Beauchesne, 1980.

Royo Mejía, Alberto. "Evolución histórica de la prueba de la heroicidad de las virtudes en las causas de los Santos en los siglos anteriores a Benedicto XIV”. Archivo Teológico Granadino 56 (1993): 25-61.

Saadan, Mohamed. "La minoría morisca en la percepción y legado escrito de Juan de Ávila”. En Juan de Ávila, unicus et multiplex. Una visión multidisciplinar, editado por $\mathrm{M}^{\mathrm{a}}$ Dolores Rincón González, Ignacio Pulido Serrano y Natalia Soria Ruiz, 733-749. Madrid: Fundación Universitaria Española, 2021.

Sala Balust, Luis y Martín Hernández, Francisco. "Estudio biográfico", en San Juan de Ávila, Obras completas I (Madrid: BAC, 2000), 3-373.

Salazar Andreu, Juan Pablo. "Fray Julián Garcés. El Defensor de los Indios (1527-1542)". Hipogrifo 4/2 (2016): 327-337.

Sánchez Herrador, Miguel Ángel y Manchón Gómez, Raúl. "La biblioteca de Juan de Ávila del colegio jesuítico de Montilla”, en El Maestro Juan de Ávila (1500?-1569). Un exponente del humanismo reformista, editado por Mª Dolores Rincón González y Raúl Manchón Gómez, 439-472. Madrid: FUE - Universidad Pontificia de Salamanca, 2014.

Silva, Álvaro. Tomás Moro. Un hombre para todas las horas. Madrid: Marcial Pons, 2007.

Sodano, Giulio. "El nuevo proceso de canonización de la edad moderna". Anuario de Historia de la Iglesia 29 (2020): 53-72.

Sodano, Giulio. "Il nuovo modello di santità nell'epoca post-tridentina". En I tempi del Concilio. Religione, cultura e società nell'Europa tridentina, a cura di Cesare Mozzarelli e Danilo Zardin, 189-205. Roma: Bulzoni Editore, 1997.

Uríbarri, Gabino. "Fundamentos teológicos del martirio cristiano", en La confesión de la fe, editado por María Encarnación González Rodríguez, 37-84. Madrid: EDICE, 2013.

Valero, Juan B. "Martirio y libertad en la primitiva Iglesia". Communio 9 (1987): 124-138.

Vidal, Senén. Las cartas originales de Pablo. Madrid: Trotta, 1996.

Vives Pérez, Pedro L. "Lectura cristológica del Tratado del amor de Dios de San Juan de Ávila”. Burgense 52/2 (2011): 375-400. 